\title{
Transposing Molecular Fluorescent Switches into the Near-IR: Development of Luminogenic Reporter Substrates for Redox Metabolism
}

\author{
Marlin Halim, Matthew S. Tremblay, Steffen Jockusch, Nicholas J. \\ Turro and Dalibor Sames* \\ Department of Chemistry, Columbia University, New York, NY 10027 \\ sames@chem.columbia.edu'
}

Supporting Information

\author{
Part I: Synthetic Methods \\ Part II: Photophysical Measurements \\ Part III: Enzymology \\ Part IV: Luminescence and Fluorescence Spectra \\ Part V: NMR of Selected Compounds
}

Part I: Synthetic Methods

\section{Materials and General methods}

Unless otherwise noted, all chemicals were purchased from Sigma-Aldrich or Strem and used without further purification. When necessary, solvents were dried by passing them through a column of alumina under argon. Flash chromatography was performed on SILICYCLE silica gel (230-400 mesh). Standard Schlenk techniques were used for airsensitive reactions. Nuclear Magnetic Resonance spectra were recorded at $300 \mathrm{~K}$ on Bruker 300 or 400 Fourier transform NMR spectrometers. Unless otherwise noted, spectra are referenced to the solvent residual peak $\left(\mathrm{CHCl}_{3}\right.$ at $\delta 7.26 \mathrm{ppm}$ and $\mathrm{CDCl}_{3}$ at $\delta$ 77.0 for $\mathrm{CDCl}_{3} ; \mathrm{CH}_{3} \mathrm{OD}$ at $\delta 3.34 \mathrm{ppm}$ and $\mathrm{CD}_{3} \mathrm{OD}$ at $\delta 49.0$ for $\mathrm{MeOH}-d_{4} ; \mathrm{H}_{2} \mathrm{O}$ at $\delta 4.79$ for $\mathrm{D}_{2} \mathrm{O}$ ). Mass spectra were recorded on a JEOL LCmate (ionization mode: APCI + ) or on a JMS-HX110 HF mass spectrometer (ionization mode: FAB + ). Preparative HPLC was performed on a Vydac C18 Protein \& Peptide column with a Waters 600 Controller; fractions were detected with a Waters 2487 Dual $\lambda$ Absorbance Detector and collected with a Waters 2767 Sample Manager. Data was analyzed using OpenLynx software. Isocratic elution or linear gradients of solvents $\mathrm{A}$ and $\mathrm{B}$ were used (A = HPLC grade acetonitrile containing $10 \%$ (v/v) de-ionized water (Millipore Simplicity 185, 18.2 M $\Omega$ ); $\mathrm{B}=$ de-ionized water containing $0.1 \%(\mathrm{v} / \mathrm{v})$ trifluoroacetic acid (ReagentPlus grade, 99\%). 


$$
\underbrace{}_{\mathrm{O}^{\prime}} \begin{aligned}
& \begin{array}{l}
\text { 1. LiHMDS, THF } \\
\frac{-78^{\circ} \mathrm{C}, 1 \mathrm{hr}}{2 . \mathrm{PhCHO}, \mathrm{THF}} \\
78^{\circ} \mathrm{C}, \mathrm{h}, 2 \mathrm{hrs}, 65 \%
\end{array}
\end{aligned}
$$<smiles>COC(=O)C#CC(O)c1ccccc1</smiles>
$\underset{\mathrm{CH}_{2} \mathrm{Cl}_{2}, \mathrm{RT}, 3 \mathrm{hrs}, 96 \%}{\stackrel{\text { Dess-Martin Periodinane }}{\longrightarrow}}$

15

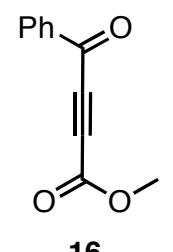

16

Scheme S1. Synthesis of intermediates 15 and $\mathbf{1 6 .}$

\section{Intermediate 15 (methyl 4-hydroxy-2-butynoate)}

Lithium bis(trimethylsilyl)-amide ( $33 \mathrm{ml}, 1.0 \mathrm{M}$ in THF, $33 \mathrm{mmol}$ ) was cooled to $-78^{\circ} \mathrm{C}$ under argon. Methyl propiolate $(2.5 \mathrm{ml}, 30 \mathrm{mmol})$ was added dropwise and the mixture was stirred at $-78^{\circ} \mathrm{C}$ for $1 \mathrm{hr}$. After $1 \mathrm{hr}$, benzaldehyde $(3.4 \mathrm{ml}, 33 \mathrm{mmol})$ was added. The reaction temperature was maintained at $-78^{\circ} \mathrm{C}$ for $2 \mathrm{hrs}$. The reaction was quenched by the addition of saturated $\mathrm{NH}_{4} \mathrm{Cl}$. The resulting mixture was extracted with EtOAc and dried over $\mathrm{MgSO}_{4}$. Following evaporation of solvent, the residue was purified by column chromatography on silica gel ( $20 \%$ EtOAc, hexane) to afford the pure product as yellow oil (3.7 g, 65\%). Spectral data are consistent with those previously published. ${ }^{1}$

\section{Intermediate 16 (methyl 4-oxo-2-butynoate)}

A solution of $0.3 \mathrm{M}$ Dess-Martin periodinane in $\mathrm{CH}_{2} \mathrm{Cl}_{2}(80 \mathrm{ml}, 24 \mathrm{mmol})$ was added dropwise to a solution of $\mathbf{1 5}(3.5 \mathrm{~g}, 18 \mathrm{mmol})$ in dry $\mathrm{CH}_{2} \mathrm{Cl}_{2}(20 \mathrm{ml})$ at RT under argon. After $2 \mathrm{hrs}$, the reaction was quenched by slow addition of saturated $\mathrm{NaHCO}_{3}(30$ $\mathrm{ml}$ ). The resulting mixture was stirred for $15 \mathrm{~min}$, extracted with $\mathrm{CH}_{2} \mathrm{Cl}_{2}$ and dried over $\mathrm{MgSO}_{4}$. Following evaporation of solvent, the residue was purified by column chromatography on silica gel (20\% EtOAc/hexane) to yield pure $\mathbf{1 6}$ as pale yellow solid $(3.3 \mathrm{~g}, 96 \%)$. Spectral data are consistent with those previously published. ${ }^{2}$

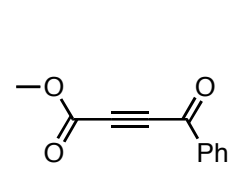

16

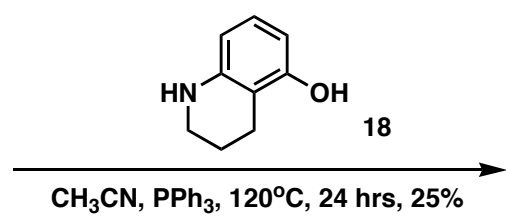<smiles>O=C(c1ccccc1)c1cc(=O)oc2cc3c(cc12)CCCN3</smiles><smiles>O=C(c1ccccc1)c1cc(=O)oc2c3c(ccc12)NCCC3</smiles>

20

Scheme S2. Synthesis of compounds 19 and 20.

\section{Compound 19}

Phenol 17 was obtained by $\mathrm{BBr}_{3}$ demethylation of 7-methoxy-1,2,3,4tetrahydroquinoline, prepared from 6-methoxy-indanone following literature procedure. ${ }^{3}$

Phenol 17 (1.13 g, $7.60 \mathrm{mmol})$, compound 16 (1.50 g, $7.98 \mathrm{mmol})$ and $\mathrm{PPh}_{3}(2.19$ $\mathrm{g}, 8.36 \mathrm{mmol})$ were dissolved in $\mathrm{CH}_{3} \mathrm{CN}(15 \mathrm{ml})$ in a sealed tube and stirred at $120^{\circ} \mathrm{C}$ for 
24 hrs. The cooled mixture was then diluted with $\mathrm{CH}_{2} \mathrm{Cl}_{2}$, washed with brine and dried over $\mathrm{MgSO}_{4}$. After evaporation of solvent, the residue was purified by column chromatography on silica gel $(15 \% \mathrm{EtOAc} /$ hexane) to give the pure product as orange solid (580 mg, 25\%). ${ }^{1} \mathrm{H}$ NMR $\left(\mathrm{CDCl}_{3}, 300 \mathrm{MHz}\right)$ : $\delta 7.96(2 \mathrm{H}, \mathrm{m}), 7.64(1 \mathrm{H}, \mathrm{m}), 7.50$ $(2 \mathrm{H}, \mathrm{m}), 6.88(1 \mathrm{H}, \mathrm{s}), 6.43(1 \mathrm{H}, \mathrm{s}), 5.97(1 \mathrm{H}, \mathrm{s}), 4.79(1 \mathrm{H}, \mathrm{bs}), 3.36(2 \mathrm{H}, \mathrm{m}), 2.65(2 \mathrm{H}, \mathrm{t}$, $J=6.2 \mathrm{~Hz}), 1.89(2 \mathrm{H}, \mathrm{m}) .{ }^{13} \mathrm{C} \mathrm{NMR}\left(\mathrm{CDCl}_{3}, 75 \mathrm{MHz}\right): \delta 194.0,161.4,155.1,152.0$, 149.1, 135.2, 134.7, 130.1, 128.9, 126.1, 118.8, 107.3, 106.5, 99.2, 41.5, 26.6, 21.0. LRMS (APCI ${ }^{+}$): Calc'd for $\mathrm{C}_{19} \mathrm{H}_{16} \mathrm{NO}_{3} 305^{\mathrm{m}} / z$, measured $306^{\mathrm{m}} / z\left(\mathbf{M H}^{+}\right)$.

\section{Compound 20}

Phenol 18 was obtained following literature procedure. ${ }^{4}$

Phenol 18 (1.13 g, $7.60 \mathrm{mmol})$, compound 16 (1.50 g, $7.98 \mathrm{mmol})$ and $\mathrm{PPh}_{3}(2.19$ g, $8.36 \mathrm{mmol})$ were dissolved in $\mathrm{CH}_{3} \mathrm{CN}(15 \mathrm{ml})$ in a sealed tube and stirred at $120^{\circ} \mathrm{C}$ for $24 \mathrm{hrs}$. The cooled mixture was then diluted with $\mathrm{CH}_{2} \mathrm{Cl}_{2}$, washed with brine and dried over $\mathrm{MgSO}_{4}$. After evaporation of solvent, the residue was purified by column chromatography on silica gel $(20 \% \mathrm{EtOAc} /$ hexane) to give the pure product as orange solid (580 mg, 25\%). ${ }^{1} \mathrm{H}$ NMR $\left(\mathrm{CDCl}_{3}, 300 \mathrm{MHz}\right): \delta 7.94(2 \mathrm{H}, \mathrm{d}, J=7.8 \mathrm{~Hz}), 7.65(1 \mathrm{H}$, t, $J=7.2 \mathrm{~Hz}), 7.49(2 \mathrm{H}, \mathrm{t}, J=7.2 \mathrm{~Hz}), 6.95(1 \mathrm{H}, \mathrm{d}, J=8.7 \mathrm{~Hz}), 6.32(1 \mathrm{H}, \mathrm{d}, J=8.7 \mathrm{~Hz})$, $6.04(1 \mathrm{H}, \mathrm{s}), 3.38(2 \mathrm{H}, \mathrm{t}, J=6.2 \mathrm{~Hz}), 2.93(2 \mathrm{H}, \mathrm{t}, J=6.2 \mathrm{~Hz}), 2.28(4 \mathrm{H}, \mathrm{bs}), 1.98(2 \mathrm{H}$, m). ${ }^{13} \mathrm{C} \mathrm{NMR}\left(\mathrm{CDCl}_{3}, 75 \mathrm{MHz}\right): \delta 194.3,162.5,153.9,153.6,149.3,135.6,135.2,130.5$, 129.4, 125.1, 112.0, 108.0, 107.4, 107.2, 41.6, 20.8, 20.2. LRMS (APCI $\left.{ }^{+}\right)$: Calc'd for $\mathrm{C}_{19} \mathrm{H}_{16} \mathrm{NO}_{3} 305^{\mathrm{m} / z}$, measured $306^{\mathrm{m}} / z\left(\boldsymbol{M} \mathrm{H}^{+}\right)$.
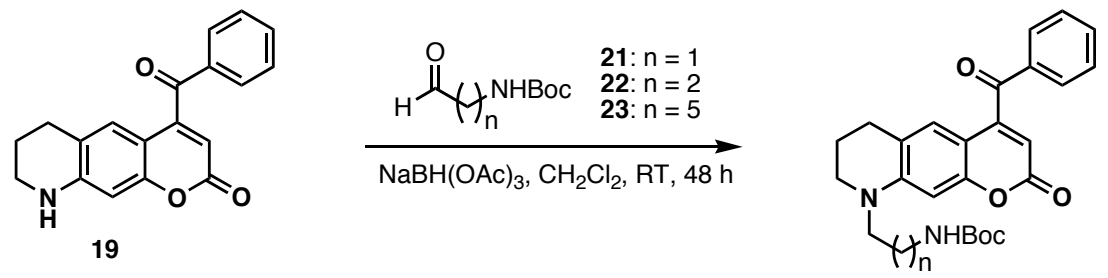

24: $n=1$

$25: n=2$
$26: n=5$
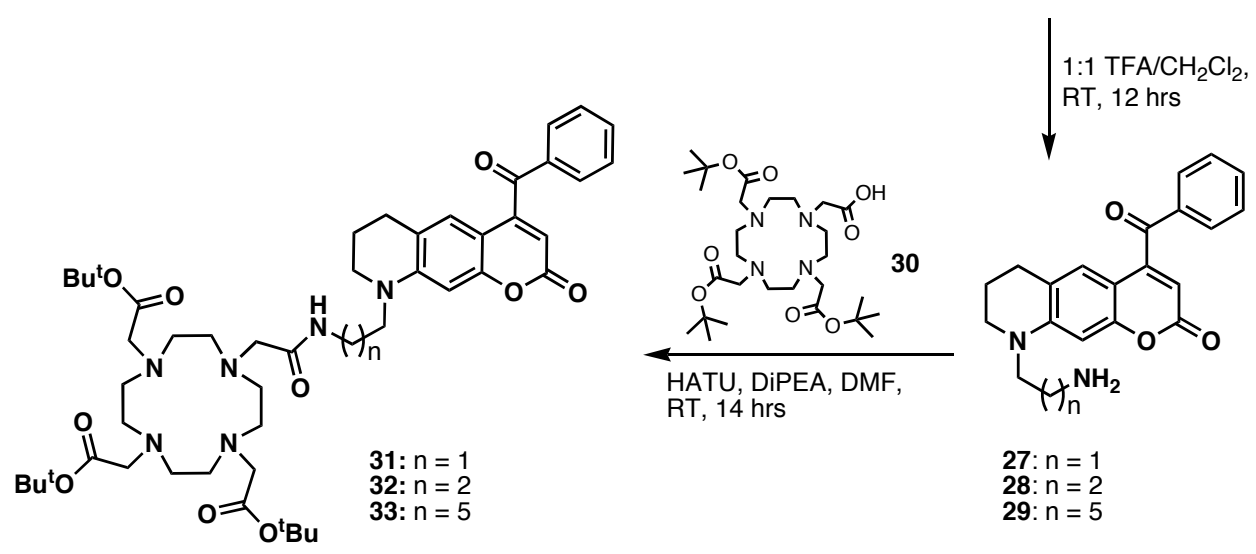

27: $n=1$

28: $n=2$

29: $n=5$

Scheme S3. Reductive amination of the coumarin 19 followed by deprotection of the Boc group and coupling with $t$-Bu protected DOTA. 

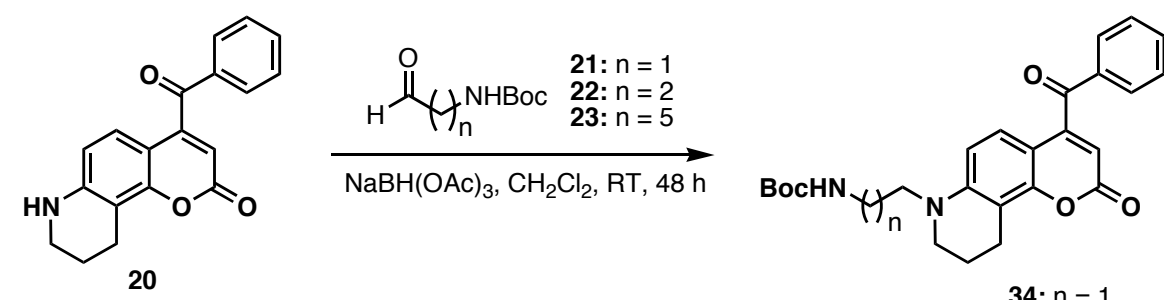

34: $\mathrm{n}=1$

35: $n=2$
36: $n=5$
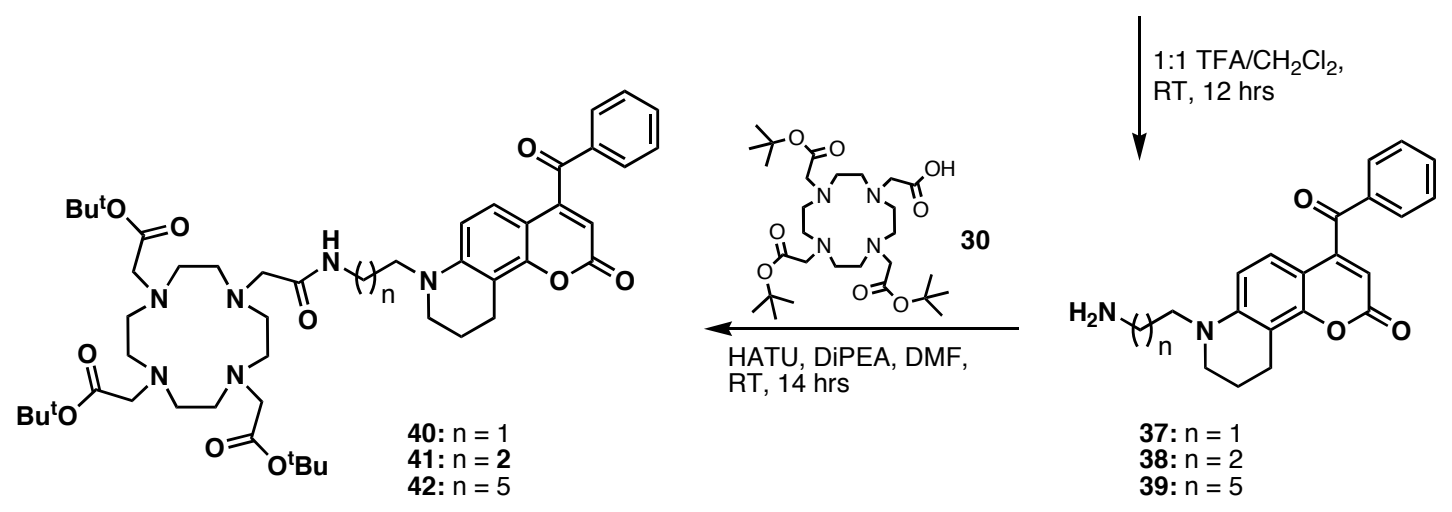

$$
\begin{aligned}
& 37: n=1 \\
& 38: n=2 \\
& 39: n=5
\end{aligned}
$$

Scheme S4. Reductive amination of the coumarin 20 followed by deprotection of the Boc group and coupling with $t$-Bu protected DOTA 30.

\section{Synthesis of 21 (2-Boc-aminoacetaldehyde)}

The aldehyde was obtained following literature procedure. ${ }^{5}$

\section{Synthesis of 22 (3-Boc-aminopropanal)}

The aldehyde was obtained following literature procedure. ${ }^{6}$

\section{Synthesis of 23 (6-(N-Boc)-aminohexanal)}

6-(N-Boc)-aminohexanoic acid (1.0 g, $4.3 \mathrm{mmol})$, TBTU (1.7 g, $5.2 \mathrm{mmol})$, N,Odimethylhydroxylamine hydrochloride $(510 \mathrm{mg}, 5.2 \mathrm{mmol})$ and $\mathrm{N}, \mathrm{N}-$ diisopropylethylamine $(3.85 \mathrm{ml}, 21.7 \mathrm{mmol})$ were dissolved in DMF and stirred at room temperature. After $8 \mathrm{hrs}$, DMF was removed in vacuo and the residue was dissolved in $\mathrm{CH}_{2} \mathrm{Cl}_{2}$, washed with $0.1 \mathrm{M} \mathrm{HCl}(3 \times 30 \mathrm{ml}), 4 \%$ aqueous $\mathrm{NaHCO}_{3}(3 \times 30 \mathrm{ml})$ and brine and dried over $\mathrm{MgSO}_{4}$. Evaporation of solvent yielded the product as pale yellow oil (1.1 g, 93\%). ${ }^{1} \mathrm{H} \mathrm{NMR}\left(\mathrm{CDCl}_{3}, 300 \mathrm{MHz}\right): \delta 4.57(1 \mathrm{H}, \mathrm{bs}), 3.65(3 \mathrm{H}, \mathrm{s}), 3.15(3 \mathrm{H}, \mathrm{s}), 3.09$ $(2 \mathrm{H}, \mathrm{m}), 2.39(2 \mathrm{H}, \mathrm{t}, J=7.5 \mathrm{~Hz}), 1.62(2 \mathrm{H}$, quint, $J=7.5 \mathrm{~Hz}), 1.25-1.52(4 \mathrm{H}, \mathrm{m}), 1.41$ $(9 \mathrm{H}, \mathrm{s}) .{ }^{13} \mathrm{C} \mathrm{NMR}\left(\mathrm{CDCl}_{3}, 75 \mathrm{MHz}\right): \delta 174.0,155.7,78.4,60.9,40.1,31.4,29.5,28.1$, 26.2, 23.9.

The oil (1.1g, $4.0 \mathrm{mmol})$ was then dissolved in dry $\mathrm{THF}$ at $-78^{\circ} \mathrm{C}$ and lithium aluminum hydride (160 mg, $4.2 \mathrm{mmol}$ ) was added in one portion. The mixture was stirred at $-78^{\circ} \mathrm{C}$ for $1.5 \mathrm{hrs}$, quenched with $1 \mathrm{M} \mathrm{HCl}$ and extracted with $\mathrm{CH}_{2} \mathrm{Cl}_{2}$. Following removal of solvent, the residue was purified by column chromatography on silica gel (25\% EtOAc/hexane) to yield a colourless oil $(530 \mathrm{mg}, 61 \%) .{ }^{1} \mathrm{H}$ NMR $\left(\mathrm{CDCl}_{3}, 300\right.$ $\mathrm{MHz}): \delta 9.78(1 \mathrm{H}, \mathrm{s}), 3.13(2 \mathrm{H}, \mathrm{m}), 2.46(2 \mathrm{H}, \mathrm{t}, J=7.2 \mathrm{~Hz}), 1.33-1.71(6 \mathrm{H}, \mathrm{m}), 1.45(9 \mathrm{H}$, s). ${ }^{13} \mathrm{C} \mathrm{NMR}\left(\mathrm{CDCl}_{3}, 75 \mathrm{MHz}\right): \delta 202.8,156.4,79.4,41.0,40.6,28.8,22.1$. 


\section{General procedure for reductive amination}

Coumarin (50 mg, $0.16 \mathrm{mmol}$ ) was dissolved in dry $\mathrm{CH}_{2} \mathrm{Cl}_{2}$ under argon at room temperature. Aldehyde (2 equiv) in $0.5 \mathrm{~mL}$ dry $\mathrm{CH}_{2} \mathrm{Cl}_{2}$ and $\mathrm{NaBH}(\mathrm{OAc})_{3}$ (1.5 equiv) were added in one portion. 2 more equiv of aldehyde and 1.5 equiv of $\mathrm{NaBH}(\mathrm{OAc})_{3}$ were added at $12 \mathrm{~h}, 24 \mathrm{~h}$ and $36 \mathrm{~h}$. The reaction was stirred for a total of $48 \mathrm{hrs}$ under argon, diluted with $\mathrm{CH}_{2} \mathrm{Cl}_{2}$, washed with $0.1 \mathrm{M} \mathrm{NaOH}$ solution $(3 \times 20 \mathrm{ml})$, brine and dried over $\mathrm{MgSO}_{4}$. After evaporation of solvent, the residue was purified by column chromatography on silica gel (20\% EtOAc/hexane).

\section{Compound 24}

Yield: $68 \%$

${ }^{1} \mathrm{H}$ NMR $\left(\mathrm{CDCl}_{3}, 300 \mathrm{MHz}\right): \delta 7.97(2 \mathrm{H}, \mathrm{d}, J=7.2 \mathrm{~Hz}), 7.67(1 \mathrm{H}, \mathrm{t}, J=7.8 \mathrm{~Hz})$, $7.51(2 \mathrm{H}, \mathrm{t}, J=7.8 \mathrm{~Hz}), 6.90(1 \mathrm{H}, \mathrm{s}), 6.40(1 \mathrm{H}, \mathrm{s}), 6.00(1 \mathrm{H}, \mathrm{s}), 4.75(1 \mathrm{H}, \mathrm{bs}), 3.36-3.74$ $(6 \mathrm{H}, \mathrm{m}), 2.66(2 \mathrm{H}, \mathrm{t}, J=6.2 \mathrm{~Hz}), 1.89(2 \mathrm{H}, \mathrm{m}), 1.50(9 \mathrm{H}, \mathrm{s}) .{ }^{13} \mathrm{C} \mathrm{NMR}\left(\mathrm{CDCl}_{3}, 75 \mathrm{MHz}\right)$ : $\delta$ 194.3, 160.7, 156.0, 152.7, 149.6, 135.5, 135.3, 130.6, 129.4, 126.0, 121.3, 108.6, 107.5, 97.0, 51.2, 50.2, 38.4, 28.6, 27.9, 21.7. LRMS (APCI ${ }^{+}$): Calc'd for $\mathrm{C}_{26} \mathrm{H}_{28} \mathrm{~N}_{2} \mathrm{O}_{5}$ $448.2 \mathrm{~m} / \mathrm{z}$, measured $449 \mathrm{~m} / \mathrm{z}\left(\boldsymbol{M H}^{+}\right)$.

\section{Compound 25}

Yield: $73 \%$

${ }^{1} \mathrm{H}$ NMR $\left(\mathrm{CDCl}_{3}, 300 \mathrm{MHz}\right): \delta 7.97(2 \mathrm{H}, \mathrm{d}, J=7.2 \mathrm{~Hz}), 7.66(1 \mathrm{H}, \mathrm{t}, J=7.8 \mathrm{~Hz})$, $7.51(2 \mathrm{H}, \mathrm{t}, J=7.8 \mathrm{~Hz}), 6.89(1 \mathrm{H}, \mathrm{s}), 6.45(1 \mathrm{H}, \mathrm{s}), 6.00(1 \mathrm{H}, \mathrm{s}), 3.22(\mathrm{bs}), 3.34-3.78(6 \mathrm{H}$, $\mathrm{m}), 2.64(2 \mathrm{H}, \mathrm{t}, J=6.2 \mathrm{~Hz}), 1.79-1.89(4 \mathrm{H}, \mathrm{m}), 1.47(9 \mathrm{H}, \mathrm{s}) .{ }^{13} \mathrm{C} \mathrm{NMR}\left(\mathrm{CDCl}_{3}, 75\right.$ $\mathrm{MHz}): \delta 194.4,162.0,156.2,152.3,149.2,135.6,135.1,130.6,129.4,125.8,120.7$, 107.5, 106.0, 97.0, 50.0, 49.5, 38.8, 28.8, 27.9, 27.1, 21.8. LRMS (APCI ${ }^{+}$): Calc'd for $\mathrm{C}_{27} \mathrm{H}_{30} \mathrm{~N}_{2} \mathrm{O}_{5} 462.2^{\mathrm{m} / z}$, measured $463 \mathrm{~m} / z\left(M \mathrm{H}^{+}\right)$.

\section{Compound 26}

Yield: $87 \%$

${ }^{1} \mathrm{H}$ NMR $\left(\mathrm{CDCl}_{3}, 300 \mathrm{MHz}\right): \delta 7.95(2 \mathrm{H}, \mathrm{m}), 7.64(1 \mathrm{H}, \mathrm{t}, J=7.2 \mathrm{~Hz}), 7.46(2 \mathrm{H}, \mathrm{t}$, $J=7.5 \mathrm{~Hz}), 6.85(1 \mathrm{H}, \mathrm{s}), 6.42(1 \mathrm{H}, \mathrm{s}), 5.94(1 \mathrm{H}, \mathrm{s}), 4.58(\mathrm{bs}), 3.24-3.48(4 \mathrm{H}, \mathrm{m}), 3.09$ $(2 \mathrm{H}, \mathrm{m}), 2.61(2 \mathrm{H}, \mathrm{m}), 1.86(2 \mathrm{H}, \mathrm{m}), 1.42(9 \mathrm{H}, \mathrm{s}), 1.33-1.63(8 \mathrm{H}, \mathrm{m}) .{ }^{13} \mathrm{C} \mathrm{NMR}\left(\mathrm{CDCl}_{3}\right.$, $75 \mathrm{MHz}): \delta 194.5,161.8,156.4,156.3,152.2,149.4,135.7,135.0,130.5,129.3,125.7$, 120.5, 107.3, 105.8, 97.0, 52.0, 49.9, 45.6, 40.9, 30.5, 28.8, 28.0, 27.2, 27.0, 26.3 21.9. LRMS (APCI ${ }^{+}$): Calc'd for $\mathrm{C}_{30} \mathrm{H}_{36} \mathrm{~N}_{2} \mathrm{O}_{5} 504.3 \mathrm{~m} / z$, measured $505^{\mathrm{m} / z}\left(\boldsymbol{M H}^{+}\right)$.

\section{Compound 34}

Yield: $68 \%$

${ }^{1} \mathrm{H} \mathrm{NMR}\left(\mathrm{CDCl}_{3}, 300 \mathrm{MHz}\right): \delta 7.95(2 \mathrm{H}, \mathrm{d}, J=7.5 \mathrm{~Hz}), 7.65(1 \mathrm{H}, \mathrm{t}, J=7.5 \mathrm{~Hz})$, $7.50(2 \mathrm{H}, \mathrm{t}, J=7.5 \mathrm{~Hz}), 7.02(1 \mathrm{H}, \mathrm{d}, J=9 \mathrm{~Hz}), 6.58(1 \mathrm{H}, \mathrm{d}, J=9 \mathrm{~Hz}), 6.03(1 \mathrm{H}, \mathrm{s}), 4.67$ (bs), 3.28-3.65 (6H, m), $2.94(2 \mathrm{H}, \mathrm{t}, J=6.2 \mathrm{~Hz}), 2.01(2 \mathrm{H}, \mathrm{m}), 1.39(9 \mathrm{H}, \mathrm{s}) .{ }^{13} \mathrm{C} \mathrm{NMR}$ $\left(\mathrm{CDCl}_{3}, 75 \mathrm{MHz}\right): \delta 194.4,162.0,156.4,153.4,153.0,149.3,135.7,135.1,130.5,129.3$, $125.4,108.9,108.3,107.5,106.7,51.3$ 50.0, 38.7, 28.7, 21.1, 20.9. LRMS (APCI $\left.{ }^{+}\right)$: Calc'd for $\mathrm{C}_{26} \mathrm{H}_{28} \mathrm{~N}_{2} \mathrm{O}_{5} 448.2 \mathrm{~m} / z$, measured $450 \mathrm{~m} / z\left(M \mathrm{H}^{+}\right)$.

\section{Compound 35}

Yield: $75 \%$

${ }^{1} \mathrm{H}$ NMR $\left(\mathrm{CDCl}_{3}, 300 \mathrm{MHz}\right): \delta 7.96(2 \mathrm{H}, \mathrm{d}, J=7.2 \mathrm{~Hz}), 7.65(1 \mathrm{H}, \mathrm{t}, J=7.5 \mathrm{~Hz})$, $7.49(2 \mathrm{H}, \mathrm{t}, J=7.5 \mathrm{~Hz}), 7.02(1 \mathrm{H}, \mathrm{d}, J=9 \mathrm{~Hz}), 6.45(1 \mathrm{H}, \mathrm{d}, J=9 \mathrm{~Hz}), 6.05(1 \mathrm{H}, \mathrm{s}), 4.59$ (bs), 3.37 (4H, m), $3.27(2 \mathrm{H}, \mathrm{m}), 2.94(2 \mathrm{H}, \mathrm{t}, J=6.3 \mathrm{~Hz}), 2.00(2 \mathrm{H}, \mathrm{m}), 1.69(2 \mathrm{H}, \mathrm{m})$, $1.43(9 \mathrm{H}, \mathrm{s}) .{ }^{13} \mathrm{C} \mathrm{NMR}\left(\mathrm{CDCl}_{3}, 75 \mathrm{MHz}\right): \delta$ 194.4, 162.3, 153.4, 153.1, 149.1, 135.7, 
135.1, 130.5, 129.2, 125.8, 109.0, 108.3, 107.3, 106.6, 49.8, 29.4, 28.8, 28.0, 21.1, 20.8. LRMS (APCI ${ }^{+}$): Calc'd for $\mathrm{C}_{27} \mathrm{H}_{30} \mathrm{~N}_{2} \mathrm{O}_{5} 462 . \mathrm{m}^{\mathrm{m}} / z$, measured $463^{\mathrm{m}} / z\left(M \mathrm{H}^{+}\right)$.

\section{Compound 36}

Yield: $86 \%$

${ }^{1} \mathrm{H}$ NMR $\left(\mathrm{CDCl}_{3}, 300 \mathrm{MHz}\right): \delta 7.95(2 \mathrm{H}, \mathrm{d}, J=7.2 \mathrm{~Hz}), 7.64(1 \mathrm{H}, \mathrm{t}, J=7.5 \mathrm{~Hz})$, $7.49(2 \mathrm{H}, \mathrm{t}, J=7.5 \mathrm{~Hz}), 7.01(1 \mathrm{H}, \mathrm{d}, J=9 \mathrm{~Hz}), 6.43(1 \mathrm{H}, \mathrm{d}, J=9 \mathrm{~Hz}), 5.99(1 \mathrm{H}, \mathrm{s}), 4.51$ (bs), 3.27-3.83 (4H, m), $3.08(2 \mathrm{H}, \mathrm{bs}), 2.92(2 \mathrm{H}, \mathrm{t}, J=6.3 \mathrm{~Hz}), 1.97(2 \mathrm{H}, \mathrm{m}), 1.57(2 \mathrm{H}$, bm), $1.42(9 \mathrm{H}, \mathrm{s}), 1.32(6 \mathrm{H}, \mathrm{bm}) .{ }^{13} \mathrm{C}$ NMR $\left(\mathrm{CDCl}_{3}, 75 \mathrm{MHz}\right): \delta 194.5,162.0,153.4$, 153.0, 149.3, 135.8, 135.0, 130.5, 129.3, 125.2, 108.6, 108.3, 107.0, 106.3, 52.1, 49.7, 40.8, 30.4, 28.8, 27.1, 27.0, 21.1, 20.9. LRMS $\left(\mathrm{APCI}^{+}\right)$: Calc'd for $\mathrm{C}_{30} \mathrm{H}_{36} \mathrm{~N}_{2} \mathrm{O}_{5} 504.3 \mathrm{~m} / z$, measured $505^{\mathrm{m} / z}\left(\boldsymbol{M} \mathrm{H}^{+}\right)$.

\section{General procedure for the deprotection of Boc group}

The corresponding Boc-protected coumarin compounds were dissolved in 1:1 mixture of dry $\mathrm{CH}_{2} \mathrm{Cl}_{2} / \mathrm{TFA}$ ( $20 \mathrm{mg}$ of compound/2 ml of mixture). The solution was stirred at room temperature for $12 \mathrm{hrs}$, the solvent removed and the residue purified on reverse-phase prep HPLC. Elution gradient is 30\% - 100\% acetonitrile in $18 \mathrm{~min}$. The yield in all cases is $>96 \%$.

\section{Compound 27}

${ }^{1} \mathrm{H}$ NMR $\left(\mathrm{CD}_{3} \mathrm{OD}, 300 \mathrm{MHz}\right): \delta 7.99(2 \mathrm{H}, \mathrm{d}, J=7.2 \mathrm{~Hz}), 7.75(1 \mathrm{H}, \mathrm{t}, J=7.5$ $\mathrm{Hz}), 7.59(2 \mathrm{H}, \mathrm{t}, J=7.5 \mathrm{~Hz}), 6.92(1 \mathrm{H}, \mathrm{s}), 6.73(1 \mathrm{H}, \mathrm{s}), 6.08(1 \mathrm{H}, \mathrm{s}), 3.73(2 \mathrm{H}, \mathrm{t}, J=6.9$ $\mathrm{Hz}), 3.47(2 \mathrm{H}, \mathrm{t}, J=5.7 \mathrm{~Hz}), 3.24(2 \mathrm{H}, \mathrm{t}, J=6.9 \mathrm{~Hz}), 2.70(2 \mathrm{H}, \mathrm{t}, J=6.0 \mathrm{~Hz}), 1.97(2 \mathrm{H}$, m). ${ }^{13} \mathrm{C}$ NMR $\left(\mathrm{CD}_{3} \mathrm{OD}, 75 \mathrm{MHz}\right): \delta 194.1,162.2,155.9,153.2,149.2,135.6,135.0$, 130.0, 129.2, 125.8, 121.6, 107.4, 106.7, 96.9, 49.8, 35.9, 27.3, 21.4. LRMS $\left(\mathrm{APCI}^{+}\right)$: Calc'd for $\mathrm{C}_{21} \mathrm{H}_{20} \mathrm{~N}_{2} \mathrm{O}_{3} 348.2 \mathrm{~m} / z$, measured $349 \mathrm{~m} / z\left(M \mathrm{H}^{+}\right)$.

\section{Compound 28}

${ }^{1} \mathrm{H}$ NMR $\left(\mathrm{CDCl}_{3}, 300 \mathrm{MHz}\right): \delta 8.82(\mathrm{bs}), 7.97(2 \mathrm{H}, \mathrm{d}, J=7.2 \mathrm{~Hz}), 7.68(1 \mathrm{H}, \mathrm{t}, J=$ $7.2 \mathrm{~Hz}), 7.52(2 \mathrm{H}, \mathrm{t}, J=7.5 \mathrm{~Hz}), 6.89(1 \mathrm{H}, \mathrm{s}), 6.77(1 \mathrm{H}, \mathrm{s}), 5.96(1 \mathrm{H}, \mathrm{s}), 3.70(2 \mathrm{H}, \mathrm{bt})$, $3.37(2 \mathrm{H}, \mathrm{bt}), 3.23(2 \mathrm{H}, \mathrm{bm}), 2.78(2 \mathrm{H}, \mathrm{bt}), 2.11(2 \mathrm{H}, \mathrm{bm}), 1.92(2 \mathrm{H}, \mathrm{bm}) .{ }^{13} \mathrm{C} \mathrm{NMR}$ $\left(\mathrm{CDCl}_{3}, 75 \mathrm{MHz}\right): \delta 194.2,163.8,156.0,153.7,149.6,135.5,135.2,130.6,129.4,125.9$, 121.3, 106.3, 106.1, 97.0, 49.4, 48.8, 38.0, 27.9, 24.1, 21.6. LRMS (APCI $\left.{ }^{+}\right)$: Calc'd for $\mathrm{C}_{22} \mathrm{H}_{22} \mathrm{~N}_{2} \mathrm{O}_{3} 362.2 \mathrm{~m} / z$, measured $363 \mathrm{~m}_{z}\left(M \mathrm{H}^{+}\right)$.

\section{Compound 29}

${ }^{1} \mathrm{H}$ NMR $\left(\mathrm{CD}_{3} \mathrm{OD}, 300 \mathrm{MHz}\right): \delta 7.97(2 \mathrm{H}, \mathrm{d}, J=6.9 \mathrm{~Hz}), 7.73(1 \mathrm{H}, \mathrm{t}, J=7.2 \mathrm{~Hz})$, $7.56(2 \mathrm{H}, \mathrm{t}, J=7.2 \mathrm{~Hz}), 6.81(1 \mathrm{H}, \mathrm{s}), 6.51(1 \mathrm{H}, \mathrm{s}), 5.94(1 \mathrm{H}, \mathrm{s}), 3.39(4 \mathrm{H}, \mathrm{m}), 2.98(2 \mathrm{H}, \mathrm{t}$, $J=7.5 \mathrm{~Hz}), 2.62(2 \mathrm{H}, \mathrm{t}, J=6 \mathrm{~Hz}), 1.88(2 \mathrm{H}, \mathrm{m}), 1.72(4 \mathrm{H}, \mathrm{m}), 1.49(4 \mathrm{H}, \mathrm{m}) .{ }^{13} \mathrm{C}$ NMR $\left(\mathrm{CD}_{3} \mathrm{OD}, 75 \mathrm{MHz}\right): \delta 194.4,162.6,156.1,153.4,149.7,135.6,135.0,130.0,129.2$, 125.4, 121.0, 105.7, 105.6, 96.3, 51.2, 49.4, 39.7, 27.5, 26.5, 26.3, 25.8, 21.5. LRMS (APCI ${ }^{+}$): Calc'd for $\mathrm{C}_{25} \mathrm{H}_{28} \mathrm{~N}_{2} \mathrm{O}_{3} 404.2^{\mathrm{m}} / z$, measured $405^{\mathrm{m}} / z\left(M \mathrm{H}^{+}\right)$.

\section{Compound 37}

${ }^{1} \mathrm{H}$ NMR $\left(\mathrm{CD}_{3} \mathrm{OD}, 300 \mathrm{MHz}\right): \delta 7.95(2 \mathrm{H}, \mathrm{d}, J=7.8 \mathrm{~Hz}), 7.71(1 \mathrm{H}, \mathrm{t}, J=7.8 \mathrm{~Hz})$, $7.55(2 \mathrm{H}, \mathrm{t}, J=7.8 \mathrm{~Hz}), 7.03(1 \mathrm{H}, \mathrm{d}, J=9 \mathrm{~Hz}), 6.68(1 \mathrm{H}, \mathrm{d}, J=9 \mathrm{~Hz}), 6.05(1 \mathrm{H}, \mathrm{s}), 3.69$ $(2 \mathrm{H}, \mathrm{t}, J=6.9 \mathrm{~Hz}), 3.45(2 \mathrm{H}, \mathrm{m}), 3.16(2 \mathrm{H}, \mathrm{t}, J=6.9 \mathrm{~Hz}), 2.92(2 \mathrm{H}, \mathrm{t}, J=6.3 \mathrm{~Hz}), 2.03$ $(2 \mathrm{H}, \mathrm{m}) .{ }^{13} \mathrm{C}$ NMR $\left(\mathrm{CD}_{3} \mathrm{OD}, 75 \mathrm{MHz}\right): \delta 194.6,162.6,154.1,153.5,149.5,136.0,135.4$, 130.5, 129.6, 125.6, 109.9, 108.7, 107.5, 49.9, 36.9, 21.0, 20.8. LRMS (APCI $\left.{ }^{+}\right)$: Calc'd for $\mathrm{C}_{21} \mathrm{H}_{20} \mathrm{~N}_{2} \mathrm{O}_{3} 348.2^{\mathrm{m}} / z$, measured $349 \mathrm{~m} / z\left(M \mathrm{H}^{+}\right)$. 


\section{Compound 38}

${ }^{1} \mathrm{H}$ NMR $\left(\mathrm{CD}_{3} \mathrm{OD}, 300 \mathrm{MHz}\right): \delta 7.98(2 \mathrm{H}, \mathrm{d}, J=7.2 \mathrm{~Hz}), 7.74(1 \mathrm{H}, \mathrm{t}, J=7.5 \mathrm{~Hz})$, $7.58(2 \mathrm{H}, \mathrm{t}, J=7.5 \mathrm{~Hz}), 7.03(1 \mathrm{H}, \mathrm{d}, J=9 \mathrm{~Hz}), 6.68(1 \mathrm{H}, \mathrm{d}, J=9 \mathrm{~Hz}), 6.05(1 \mathrm{H}, \mathrm{s}), 3.38-$ $3.55(4 \mathrm{H}, \mathrm{m}), 2.90-3.04(4 \mathrm{H}, \mathrm{m}), 1.93-2.08(4 \mathrm{H}, \mathrm{m}) .{ }^{13} \mathrm{C} \mathrm{NMR}\left(\mathrm{CD}_{3} \mathrm{OD}, 75 \mathrm{MHz}\right): \delta$ $194.3,162.4,153.9,153.5,149.2,135.7,135.0,130.0,129.2,125.1,108.7,108.4,106.5$, 106.3, 49.2, 37.5, 25.0, 20.7, 20.4. LRMS (APCI ${ }^{+}$): Calc'd for $\mathrm{C}_{22} \mathrm{H}_{22} \mathrm{~N}_{2} \mathrm{O}_{5} 362.2 \mathrm{~m} / z$, measured $363^{\mathrm{m} / z}\left(\boldsymbol{M} \mathrm{H}^{+}\right)$.

Compound 39

${ }^{1} \mathrm{H}$ NMR $\left(\mathrm{CD}_{3} \mathrm{OD}, 300 \mathrm{MHz}\right): \delta 7.97(2 \mathrm{H}, \mathrm{d}, J=7.2 \mathrm{~Hz}), 7.73(1 \mathrm{H}, \mathrm{t}, J=7.2 \mathrm{~Hz})$, $7.57(2 \mathrm{H}, \mathrm{t}, J=7.2 \mathrm{~Hz}), 6.98(1 \mathrm{H}, \mathrm{d}, J=9 \mathrm{~Hz}), 6.61(1 \mathrm{H}, \mathrm{d}, J=9 \mathrm{~Hz}), 5.98(1 \mathrm{H}, \mathrm{s}), 3.43$ $(4 \mathrm{H}, \mathrm{m}), 2.91(4 \mathrm{H}, \mathrm{m}), 2.00(2 \mathrm{H}, \mathrm{m}), 1.65(4 \mathrm{H}, \mathrm{m}), 1.44(4 \mathrm{H}, \mathrm{m}) .{ }^{13} \mathrm{C} \mathrm{NMR}\left(\mathrm{CD}_{3} \mathrm{OD}, 75\right.$ $\mathrm{MHz}): \delta 194.5,162.6,154.0,153.2,149.6,135.7,134.9,130.0,129.2,125.0,108.5$, 108.1, 106.0, 105.4, 51.3, 49.2, 39.6, 27.5, 26.5, 26.3, 20.7, 20.5. LRMS (APCI $\left.{ }^{+}\right)$: Calc'd for $\mathrm{C}_{25} \mathrm{H}_{28} \mathrm{~N}_{2} \mathrm{O}_{3} 404.2 \mathrm{~m} / z$, measured $406^{\mathrm{m} / z}\left(\boldsymbol{M} \mathrm{H}^{+}\right)$.

\section{Synthesis of acid 30}

The compound was obtained following a literature procedure. ${ }^{7}$

\section{General procedure for coupling reaction with $\mathbf{3 0}$}

Amine (1 equiv), HATU (1.3 equiv), Compound 30 (1.3 equiv) and diisopropylethylamine (10 equiv) were dissolved in DMF and stirred for $12 \mathrm{hrs}$ at room temperature. After removal of solvent, the residue was purified on reverse-phase prep HPLC. Elution gradient is 20\% - 100\% acetonitrile in $35 \mathrm{~min}$. Broadening of peaks in the region of $2-4.50 \mathrm{ppm}$ was observed in the ${ }^{1} \mathrm{H}$ NMR of macrocyclic compounds.

\section{Compound 31}

${ }^{1} \mathrm{H} \mathrm{NMR}\left(\mathrm{CDCl}_{3}, 300 \mathrm{MHz}\right): \delta 7.95(2 \mathrm{H}, \mathrm{d}, J=7.8 \mathrm{~Hz}), 7.65(1 \mathrm{H}, \mathrm{m}), 7.51(2 \mathrm{H}$, m), $6.92(1 \mathrm{H}, 2), 6.45(1 \mathrm{H}, \mathrm{s}), 5.96(1 \mathrm{H}, \mathrm{s}), 2.84-4.30(32 \mathrm{H}, \mathrm{bm}), 1.95(2 \mathrm{H}, \mathrm{bs}), 1.18$ $1.50(27 \mathrm{H}, \mathrm{m})$ LRMS $\left(\mathrm{APCI}^{+}\right)$: Calc'd for $\mathrm{C}_{49} \mathrm{H}_{70} \mathrm{~N}_{6} \mathrm{O}_{10} 902^{\mathrm{m} / z}$, measured $903 \mathrm{~m} / z\left(\mathrm{MH}^{+}\right)$.

\section{Compound 32}

${ }^{1} \mathrm{H} \mathrm{NMR}\left(\mathrm{CDCl}_{3}, 300 \mathrm{MHz}\right): \delta 7.96(2 \mathrm{H}, \mathrm{d}, J=7.8 \mathrm{~Hz}), 7.66(1 \mathrm{H}, \mathrm{m}), 7.53(2 \mathrm{H}$, m), $6.85(1 \mathrm{H}, \mathrm{s}), 6.37(1 \mathrm{H}, \mathrm{s}), 5.94(1 \mathrm{H}, \mathrm{s}), 3.26-4.20(32 \mathrm{H}, \mathrm{bm}), 2.65(2 \mathrm{H}, \mathrm{bs}), 2.03$ (2H, bs), 1.39 - $1.88(27 \mathrm{H}, \mathrm{m}) .{ }^{13} \mathrm{C} \mathrm{NMR}\left(\mathrm{CDCl}_{3}, 75 \mathrm{MHz}\right): \delta$ 194.5, 162.0, 161.4, 160.9, 156.1 152.6, 149.5, 135.5, 135.2, 130.6, 129.4, 125.8, 120.9, 118.2, 116.9, 114.3, 107.0, $105.9,96.7,85.5,83.0,55.7,54.5,52.1,51.2,50.1,49.7,49.4,48.9,37.6,28.3,27.9$, 25.5, 21.8. LRMS (APCI ${ }^{+}$): Calc'd for $\mathrm{C}_{50} \mathrm{H}_{72} \mathrm{~N}_{6} \mathrm{O}_{10} 916^{\mathrm{m} / z}$, measured $917^{\mathrm{m} / z}\left(\boldsymbol{M H}^{+}\right)$.

\section{Compound 33}

${ }^{1} \mathrm{H} \mathrm{NMR}\left(\mathrm{CDCl}_{3}, 300 \mathrm{MHz}\right): \delta 7.96(2 \mathrm{H}, \mathrm{d}, J=7.8 \mathrm{~Hz}), 7.65(1 \mathrm{H}, \mathrm{m}), 7.50(2 \mathrm{H}$, $\mathrm{t}, J=7.2 \mathrm{~Hz}), 6.85(1 \mathrm{H}, \mathrm{s}), 6.41(1 \mathrm{H}, \mathrm{s}), 5.94(1 \mathrm{H}, \mathrm{s}), 2.62-4.1(32 \mathrm{H}, \mathrm{bm}), 1.87(2 \mathrm{H}, \mathrm{bs})$, $1.37-1.50(35 \mathrm{H}, \mathrm{m}) .{ }^{13} \mathrm{C} \mathrm{NMR}\left(\mathrm{CDCl}_{3}, 75 \mathrm{MHz}\right): \delta 194.5,162.1,161.4,160.9,160.5$ $156.2,152.5,149.5,135.6,135.1,130.5,129.3,125.7,120.7,118.2,114.3,106.8,105.8$, 96.8, 82.9, 54.5, 51.9, 49.8, 40.0, 29.4, 28.4, 28.3, 28.0, 27.1, 27.0, 26.1, 21.8. LRMS $\left(\mathrm{APCI}^{+}\right.$): Calc'd for $\mathrm{C}_{53} \mathrm{H}_{78} \mathrm{~N}_{6} \mathrm{O}_{10} 959^{\mathrm{m} / z}$, measured $960 \mathrm{~m} / z\left(\boldsymbol{M H}^{+}\right)$. 


\section{Compound 40}

${ }^{1} \mathrm{H} \mathrm{NMR}\left(\mathrm{CDCl}_{3}, 300 \mathrm{MHz}\right): \delta 7.94(2 \mathrm{H}, \mathrm{d}, J=7.8 \mathrm{~Hz}), 7.66(1 \mathrm{H}, \mathrm{t}, J=6.9 \mathrm{~Hz})$, $7.50(2 \mathrm{H}, \mathrm{t}, J=7.2 \mathrm{~Hz}), 6.98(1 \mathrm{H}, \mathrm{d}, J=9 \mathrm{~Hz}), 6.69(1 \mathrm{H}, \mathrm{d}, J=9 \mathrm{~Hz}), 5.99(1 \mathrm{H}, \mathrm{s}), 2.82$ - $3.99(32 \mathrm{H}, \mathrm{bm}), 1.97(2 \mathrm{H}, \mathrm{bs}), 1.35-1.50(27 \mathrm{H}, \mathrm{m}) .{ }^{13} \mathrm{C}$ NMR $\left(\mathrm{CDCl}_{3}, 75 \mathrm{MHz}\right): \delta$ 194.3, 162.0, 161.5, 161.0, 160.5, 153.4, 153.0, 149.6, 135.5, 135.2, 130.5, 129.4, 125.2, 122.0, 118.2, 114.3, 110.5, 108.9, 108.5, 107.2, 106.4, 85.7, 82.8, 54.4, 52.0, 49.4, 36.6, 28.3, 20.8. LRMS (APCI $)$ : Calc'd for $\mathrm{C}_{49} \mathrm{H}_{70} \mathrm{~N}_{6} \mathrm{O}_{10} 902 \mathrm{~m} / z$, measured $903 \mathrm{~m}_{z}\left(\boldsymbol{M H}^{+}\right)$.

\section{Compound 41}

${ }^{1} \mathrm{H}$ NMR $\left(\mathrm{CDCl}_{3}, 300 \mathrm{MHz}\right): \delta 7.93(2 \mathrm{H}, \mathrm{d}, J=7.8 \mathrm{~Hz}), 7.65(1 \mathrm{H}, \mathrm{t}, J=7.5 \mathrm{~Hz})$, $7.49(2 \mathrm{H}, \mathrm{t}, J=7.5 \mathrm{~Hz}), 6.98(1 \mathrm{H}, \mathrm{d}, J=9 \mathrm{~Hz}), 6.45(1 \mathrm{H}, \mathrm{d}, J=9 \mathrm{~Hz}), 5.98(1 \mathrm{H}, \mathrm{s}), 2.89$ - $3.97(32 \mathrm{H}, \mathrm{bm}), 1.95(2 \mathrm{H}, \mathrm{bs}), 1.81(2 \mathrm{H}, \mathrm{bs}), 1.34-1.48(27 \mathrm{H}, \mathrm{m}) .{ }^{13} \mathrm{C} \mathrm{NMR}\left(\mathrm{CDCl}_{3}\right.$, $75 \mathrm{MHz}): \delta 194.5,161.9,161.6,161.1,160.6,153.4,153.0,149.2,135.6,135.1,130.5$, 129.3, 125.2, 122.2, 118.3, 114.5, 110.6, 108.8, 108.3 107.1, 106.3, 85.3, 82.7, 54.4, 52.0, 49.6, 37.5, 28.2, 20.9. LRMS (APCI ${ }^{+}$): Calc'd for $\mathrm{C}_{50} \mathrm{H}_{72} \mathrm{~N}_{6} \mathrm{O}_{10} 916^{\mathrm{m}} / \mathrm{z}$, measured $917^{\mathrm{m}} / \mathrm{z}$ $\left(M \mathrm{H}^{+}\right)$.

\section{Compound 42}

${ }^{1} \mathrm{H}$ NMR $\left(\mathrm{CDCl}_{3}, 300 \mathrm{MHz}\right): \delta 7.94(2 \mathrm{H}, \mathrm{d}, J=7.8 \mathrm{~Hz}), 7.64(1 \mathrm{H}, \mathrm{t}, J=7.2 \mathrm{~Hz})$, $7.49(2 \mathrm{H}, \mathrm{t}, J=7.2 \mathrm{~Hz}), 6.99(1 \mathrm{H}, \mathrm{d}, J=9 \mathrm{~Hz}), 6.43(1 \mathrm{H}, \mathrm{d}, J=9 \mathrm{~Hz}), 5.98(1 \mathrm{H}, \mathrm{s}), 2.84$ - $4.04(32 \mathrm{H}, \mathrm{bm}), 1.96(2 \mathrm{H}, \mathrm{bs}), 1.38-1.49(35 \mathrm{H}, \mathrm{m}) .{ }^{13} \mathrm{C} \mathrm{NMR}\left(\mathrm{CDCl}_{3}, 75 \mathrm{MHz}\right): \delta$ 194.5, 162.1 161.5, 161.0, 160.5, 153.4, 153.0, 149.3, 135.7, 135.1, 130.5, 129.3, 125.2, 122.0, 118.2, 114.3, 110.5, 108.6, 108.3 106.9, 106.2, 85.4, 82.9, 54.4, 52.0, 49.7, 40.0, 29.4, 28.4, 28.3, 27.1, 27.0, 21.0, 20.9. LRMS $\left(\mathrm{APCI}^{+}\right)$: Calc'd for $\mathrm{C}_{53} \mathrm{H}_{78} \mathrm{~N}_{6} \mathrm{O}_{10} 959 \mathrm{~m} / \mathrm{z}$, measured $960 \mathrm{~m} / z\left(M \mathrm{H}^{+}\right)$.

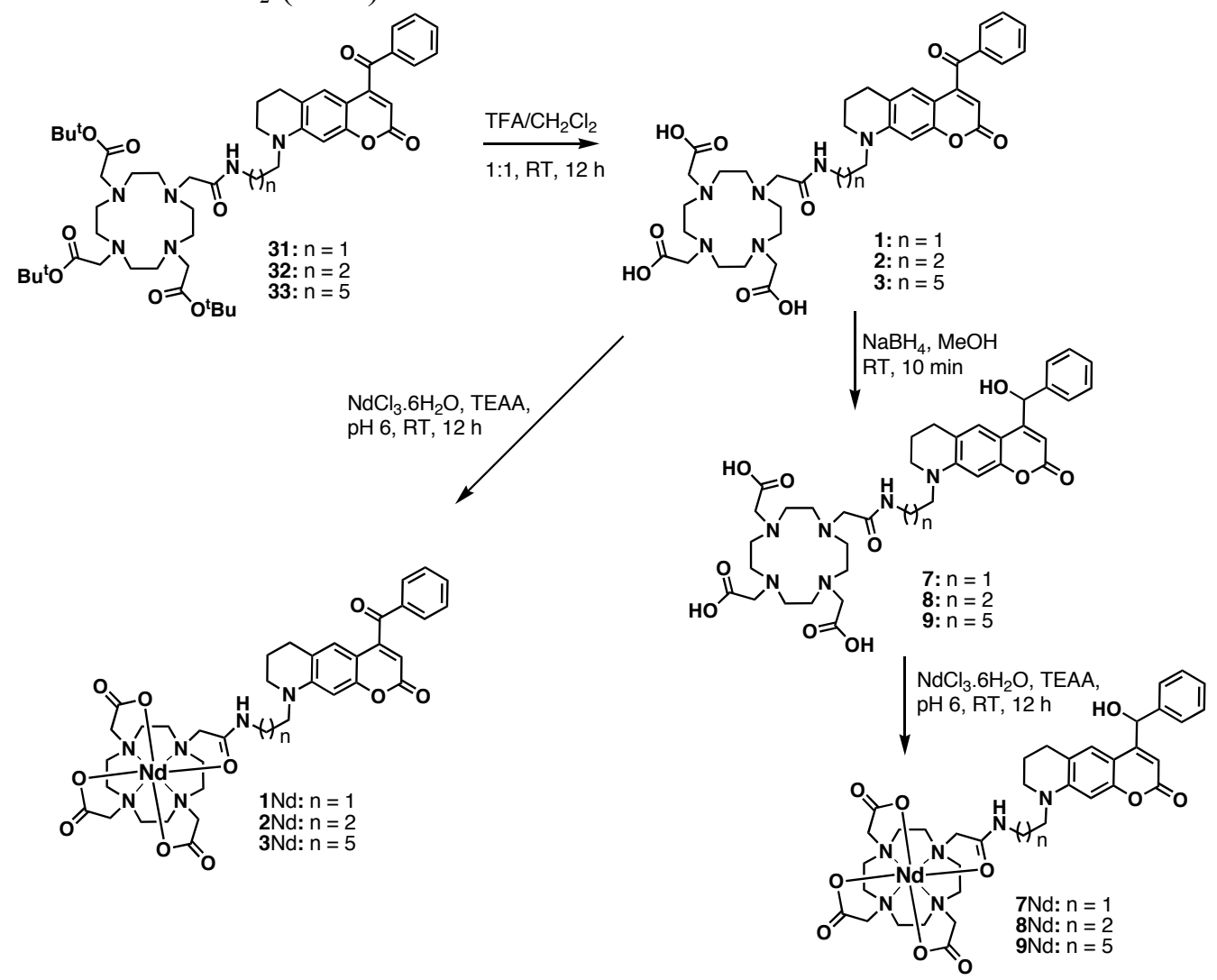

Scheme S5. Synthesis of complexes $\mathbf{1 N d}, \mathbf{2 N d}, \mathbf{3 N d}, 7 \mathrm{Nd}, \mathbf{8 N d}$ and $\mathbf{9 N d}$. 


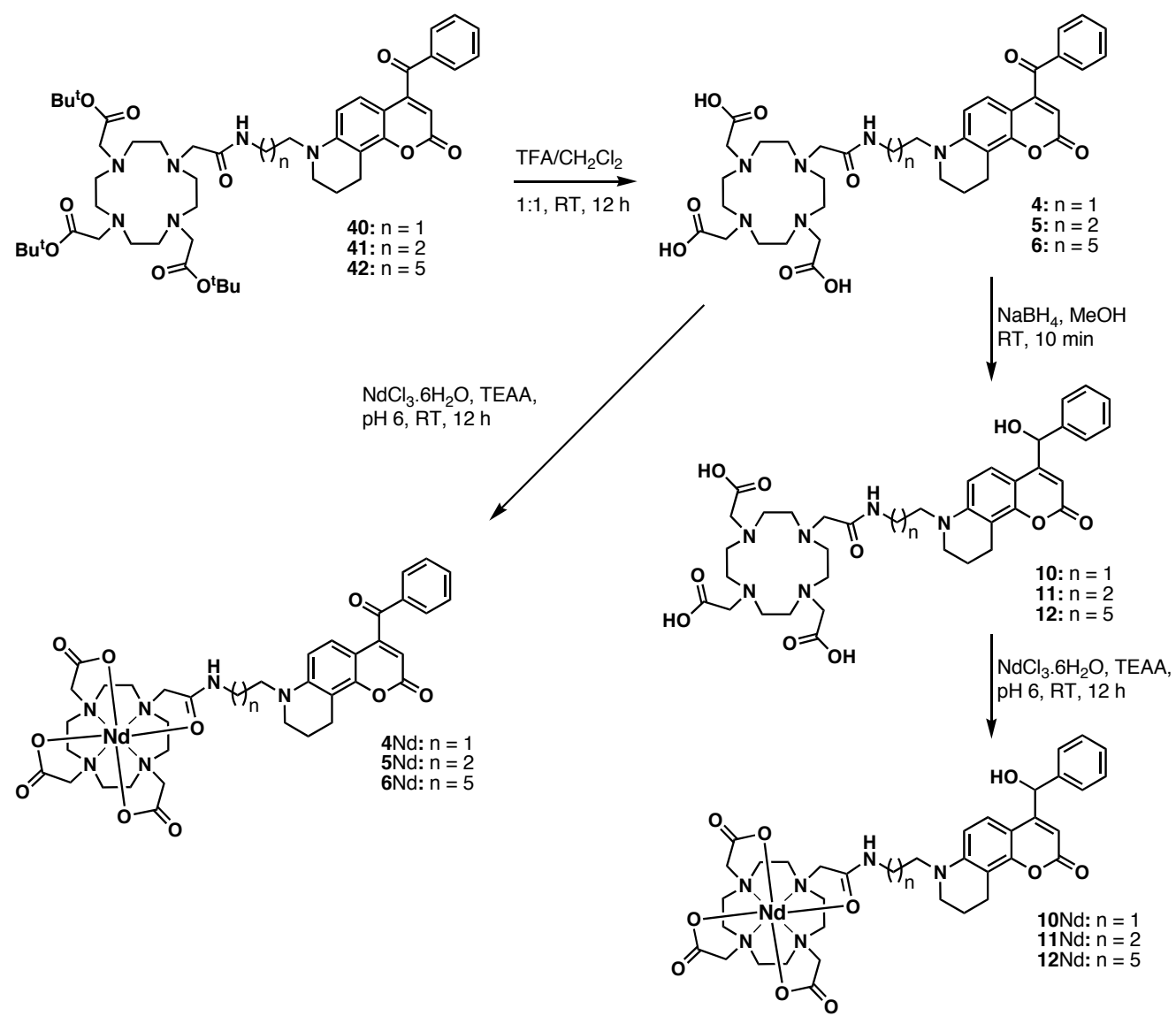

Scheme S6. Synthesis of complexes $4 \mathrm{Nd}, 5 \mathrm{Nd}, \mathbf{6 N d}, \mathbf{1 0 N d}, \mathbf{1 1} \mathrm{Nd}$ and $\mathbf{1 2} \mathrm{Nd}$.

\section{General procedure for the deprotection of $\boldsymbol{t}$-butyl esters}

The corresponding $t$-butyl ester protected macrocycles were dissolved in 1:1 mixture of dry $\mathrm{CH}_{2} \mathrm{Cl}_{2} / \mathrm{TFA}$ ( $5 \mathrm{mg}$ of compound/2 $\mathrm{ml}$ of mixture). The solution was stirred at room temperature for $12 \mathrm{hrs}$, the solvent removed and the residue purified on reverse-phase prep HPLC. Elution gradient was 3\% - 45\% acetonitrile in 17 min. Shoulders in the ${ }^{1} \mathrm{H}$ NMR peaks were observed for some of the compounds and this may be due to the rotamers. When the spectra were taken in $\mathrm{D}_{2} \mathrm{O}$, broadening of peaks also occurred.

\section{Compound 1}

${ }^{1} \mathrm{H} \mathrm{NMR}\left(\mathrm{CD}_{3} \mathrm{OD}, 300 \mathrm{MHz}\right): \delta 7.98(2 \mathrm{H}, \mathrm{d}, J=7.2 \mathrm{~Hz}), 7.76(1 \mathrm{H}, \mathrm{m}), 7.59(2 \mathrm{H}$, $\mathrm{m}), 6.85(2 \mathrm{H}, \mathrm{bs}), 6.00(1 \mathrm{H}, \mathrm{bs}), 2.68-4.01(\mathrm{~m}), 1.94(2 \mathrm{H}, \mathrm{m})$. LRMS (APCI $\left.{ }^{+}\right)$: Calc'd for $\mathrm{C}_{37} \mathrm{H}_{46} \mathrm{~N}_{6} \mathrm{O}_{10} 734 \mathrm{~m} / z$, measured $735 \mathrm{~m}_{z}\left(M \mathrm{H}^{+}\right)$.

\section{Compound 2}

${ }^{1} \mathrm{H}$ NMR ( $\left.\mathrm{D}_{2} \mathrm{O}, 300 \mathrm{MHz}\right): \delta 7.77(2 \mathrm{H}, \mathrm{bs}), 7.56(1 \mathrm{H}, \mathrm{bs}), 7.37(2 \mathrm{H}, \mathrm{bs}), 6.63(1 \mathrm{H}$, bs), $6.48(1 \mathrm{H}, \mathrm{bs}), 5.84(1 \mathrm{H}, \mathrm{bs}), 3.30-3.75(32 \mathrm{H}, \mathrm{bm}), 2.26(2 \mathrm{H}, \mathrm{bs}), 1.82(2 \mathrm{H}, \mathrm{bs}), 1.64$ $(2 \mathrm{H}, \mathrm{bs})$. LRMS $\left(\mathrm{FAB}^{+}\right)$: Calc'd for $\mathrm{C}_{38} \mathrm{H}_{48} \mathrm{~N}_{6} \mathrm{O}_{10} 748^{\mathrm{m} / z}$, measured $749^{\mathrm{m} / z}\left(\boldsymbol{M} \mathrm{H}^{+}\right)$.

\section{Compound 3}

${ }^{1} \mathrm{H}$ NMR $\left(\mathrm{D}_{2} \mathrm{O}, 300 \mathrm{MHz}\right): \delta 7.93$ (2H, bs), 7.38 (1H, bs), $7.21(2 \mathrm{H}, \mathrm{bs}), 6.54(1 \mathrm{H}$, bs), $6.27(1 \mathrm{H}, \mathrm{bs}), 5.67(1 \mathrm{H}, \mathrm{bs}), 2.89-3.75(32 \mathrm{H}, \mathrm{bm}), 2.09(2 \mathrm{H}, \mathrm{bs}), 1.16-1.49(10 \mathrm{H}$, bm). LRMS $\left(\mathrm{FAB}^{+}\right)$: Calc'd for $\mathrm{C}_{41} \mathrm{H}_{54} \mathrm{~N}_{6} \mathrm{O}_{10} 790^{\mathrm{m} / z}$, measured $791^{\mathrm{m} / z}\left(\boldsymbol{M} \mathrm{H}^{+}\right)$. 


\section{Compound 4}

${ }^{1} \mathrm{H}$ NMR $\left(\mathrm{D}_{2} \mathrm{O}, 300 \mathrm{MHz}\right): \delta 7.93(2 \mathrm{H}, \mathrm{d}, J=7.5 \mathrm{~Hz}), 7.78(1 \mathrm{H}, \mathrm{t}, J=7.2 \mathrm{~Hz})$, $7.57(2 \mathrm{H}, \mathrm{t}, J=7.2 \mathrm{~Hz}), 6.93(1 \mathrm{H}, \mathrm{d}, J=9 \mathrm{~Hz}), 6.74(1 \mathrm{H}, \mathrm{d}, J=9 \mathrm{~Hz}), 6.08(1 \mathrm{H}, \mathrm{s}), 1.95$ - $4.22(32 \mathrm{H}, \mathrm{bm}), 1.95(2 \mathrm{H}, \mathrm{bs}), 1.37(1 \mathrm{H}, \mathrm{m})$. LRMS $\left(\mathrm{FAB}^{+}\right)$: Calc'd for $\mathrm{C}_{37} \mathrm{H}_{46} \mathrm{~N}_{6} \mathrm{O}_{10}$ $734 \mathrm{~m} / \mathrm{z}$, measured $735^{\mathrm{m} / z}\left(\boldsymbol{M} \mathrm{H}^{+}\right)$.

\section{Compound 5}

${ }^{1} \mathrm{H}$ NMR $\left(\mathrm{D}_{2} \mathrm{O}, 300 \mathrm{MHz}\right): \delta 7.73-7.82(3 \mathrm{H}, \mathrm{bm}), 7.50(2 \mathrm{H}, \mathrm{bt}), 6.81(1 \mathrm{H}, \mathrm{d}, J=$ $9 \mathrm{~Hz}), 6.55(1 \mathrm{H}, \mathrm{d}, J=9 \mathrm{~Hz}), 5.99(1 \mathrm{H}, \mathrm{s}), 2.77-3.88$ (32H, bm), $1.82-1.92$ (4H, bm). LRMS (FAB $\left.{ }^{+}\right)$: Calc'd for $\mathrm{C}_{38} \mathrm{H}_{48} \mathrm{~N}_{6} \mathrm{O}_{10} 748^{\mathrm{m}} / z$, measured $749 \mathrm{~m} / z\left(\boldsymbol{M H}^{+}\right)$.

\section{Compound 6}

${ }^{1} \mathrm{H}$ NMR $\left(\mathrm{D}_{2} \mathrm{O}, 300 \mathrm{MHz}\right): \delta 7.22-7.65(5 \mathrm{H}, \mathrm{bm}), 6.59(1 \mathrm{H}, \mathrm{bs}), 6.13(1 \mathrm{H}, \mathrm{bs})$, $5.64(1 \mathrm{H}, \mathrm{bs}), 2.51-3.79(32 \mathrm{H}, \mathrm{bm}), 1.20-1.80(12 \mathrm{H}, \mathrm{bm})$. LRMS (FAB $\left.{ }^{+}\right)$: Calc'd for $\mathrm{C}_{41} \mathrm{H}_{54} \mathrm{~N}_{6} \mathrm{O}_{10} 790 \mathrm{~m} / z$, measured $791 \mathrm{~m} / z\left(\boldsymbol{M H}^{+}\right)$.

\section{General procedure for the reduction of ketone to alcohol}

The ketone unprotected macrocycle was dissolved in dry methanol and $\mathrm{NaBH}_{4}$ was added (10 equiv). The solution was stirred at room temperature for $10 \mathrm{~min}$, the solvent removed and the residue purified on reverse-phase prep HPLC. Elution gradient was 3\% - 45\% acetonitrile in 17 min. Shoulders in the ${ }^{1} \mathrm{H}$ NMR peaks were observed for some of the compounds and this may be due to the rotamers. When the spectra were taken in $\mathrm{D}_{2} \mathrm{O}$, broadening of peaks also occurred.

\section{Compound 7}

${ }^{1} \mathrm{H}$ NMR $\left(\mathrm{CD}_{3} \mathrm{OD}, 300 \mathrm{MHz}\right): \delta 7.17$ - $7.64(6 \mathrm{H}, \mathrm{bm}), 6.45(2 \mathrm{H}, \mathrm{bs}), 6.02(1 \mathrm{H}, \mathrm{s})$, 2.61 - 3.57(bm), $1.90(2 \mathrm{H}, \mathrm{m})$. LRMS $\left(\mathrm{APCI}^{+}\right)$: Calc'd for $\mathrm{C}_{37} \mathrm{H}_{48} \mathrm{~N}_{6} \mathrm{O}_{10} 736 \mathrm{~m} / \mathrm{z}_{\mathrm{z}}$, measured $737^{\mathrm{m} / z}\left(\boldsymbol{M} \mathrm{H}^{+}\right)$.

\section{Compound 8}

${ }^{1} \mathrm{H}$ NMR $\left(\mathrm{D}_{2} \mathrm{O}, 300 \mathrm{MHz}\right): \delta 7.44-7.54(5 \mathrm{H}, \mathrm{bm}), 7.17(1 \mathrm{H}, \mathrm{s}), 6.43(2 \mathrm{H}, \mathrm{m})$, $6.14(1 \mathrm{H}, \mathrm{s}), 2.59$ - $3.85(32 \mathrm{H}, \mathrm{bm}), 1.89(4 \mathrm{H}, \mathrm{bm})$. LRMS (FAB $\left.{ }^{+}\right)$: Calc'd for $\mathrm{C}_{38} \mathrm{H}_{50} \mathrm{~N}_{6} \mathrm{O}_{10} 750 \mathrm{~m} / z$, measured $751 \mathrm{~m} / z\left(M \mathrm{H}^{+}\right)$.

\section{Compound 9}

${ }^{1} \mathrm{H}$ NMR $\left(\mathrm{CD}_{3} \mathrm{OD}, 300 \mathrm{MHz}\right): \delta 7.32$ - $7.49(5 \mathrm{H}, \mathrm{m}), 7.17(1 \mathrm{H}, \mathrm{s}), 6.44(1 \mathrm{H}, \mathrm{s})$, $6.36(1 \mathrm{H}, \mathrm{s}), 6.02(1 \mathrm{H}, \mathrm{s}), 2.36-4.01(58 \mathrm{H}, \mathrm{bm}), 1.13-1.90(12 \mathrm{H}, \mathrm{bm})$. LRMS $\left(\mathrm{FAB}^{+}\right)$: Calc'd for $\mathrm{C}_{41} \mathrm{H}_{56} \mathrm{~N}_{6} \mathrm{O}_{10} 792 \mathrm{~m} / z$, measured $793 \mathrm{~m}_{z}\left(\boldsymbol{M} \mathrm{H}^{+}\right)$.

\section{Compound 10}

${ }^{1} \mathrm{H}$ NMR $\left(\mathrm{D}_{2} \mathrm{O}, 300 \mathrm{MHz}\right): \delta 7.48$ - $7.61(5 \mathrm{H}, \mathrm{m}), 7.29(1 \mathrm{H}, \mathrm{d}, J=8.7 \mathrm{~Hz}), 6.74$ $(1 \mathrm{H}, \mathrm{d}, J=9 \mathrm{~Hz}), 6.56(1 \mathrm{H}, \mathrm{s}), 6.09(1 \mathrm{H}, \mathrm{s}), 2.60-4.22(32 \mathrm{H}, \mathrm{bm}), 1.90(2 \mathrm{H}, \mathrm{bs}), 1.37$ $(1 \mathrm{H}, \mathrm{m})$. LRMS $\left(\mathrm{FAB}^{+}\right)$: Calc'd for $\mathrm{C}_{37} \mathrm{H}_{48} \mathrm{~N}_{6} \mathrm{O}_{10} 736^{\mathrm{m} / z}$, measured $737^{\mathrm{m} / z}\left(\boldsymbol{M H}^{+}\right)$.

\section{Compound 11}

${ }^{1} \mathrm{H}$ NMR ( $\left.\mathrm{D}_{2} \mathrm{O}, 300 \mathrm{MHz}\right): \delta 7.45$ - $7.52(5 \mathrm{H}, \mathrm{bm}), 7.20(1 \mathrm{H}, \mathrm{bd}), 6.56(2 \mathrm{H}, \mathrm{bs})$, $6.11(1 \mathrm{H}, \mathrm{s}), 2.77-4.20(34 \mathrm{H}, \mathrm{bm}), 1.83$ - $1.92(4 \mathrm{H}, \mathrm{bd})$. LRMS (FAB $\left.{ }^{+}\right)$: Calc'd for $\mathrm{C}_{38} \mathrm{H}_{50} \mathrm{~N}_{6} \mathrm{O}_{10} 750 \mathrm{~m} / z$, measured $751 \mathrm{~m} / z\left(M \mathrm{H}^{+}\right)$.

\section{Compound 12}

${ }^{1} \mathrm{H}$ NMR $\left(\mathrm{CD}_{3} \mathrm{OD}, 300 \mathrm{MHz}\right): \delta 7.35-7.45(6 \mathrm{H}, \mathrm{m}), 6.56(1 \mathrm{H}, \mathrm{d}, J=9 \mathrm{~Hz}), 6.38$ $(1 \mathrm{H}, \mathrm{s}), 6.03(1 \mathrm{H}, \mathrm{s}), 2.80-4.05(\mathrm{bm}), 2.06(2 \mathrm{H}, \mathrm{bt}), 1.32$ - $1.70(12 \mathrm{H}, \mathrm{bm})$. LRMS $\left(\mathrm{FAB}^{+}\right)$: Calc'd for $\mathrm{C}_{41} \mathrm{H}_{56} \mathrm{~N}_{6} \mathrm{O}_{10} 792 \mathrm{~m} / z$, measured $793 \mathrm{~m} / z\left(\boldsymbol{M H}^{+}\right)$. 


\section{General procedure for complexation with $\mathrm{NdCl}_{3} \cdot \mathbf{6} \mathrm{H}_{2} \mathrm{O}$}

The DOTA free acid macrocycle was dissolved in triethylammonium acetate buffer $\mathrm{pH}$ 6. $\mathrm{NdCl}_{3} \cdot 6 \mathrm{H}_{2} \mathrm{O}$ (3 equiv) was added and the solution stirred at room temperature for $12 \mathrm{hrs}$. The product was purified on reverse-phase prep HPLC. Elution gradient was $3 \%-45 \%$ acetonitrile in $17 \mathrm{~min}$. The fraction containing the product was collected, dried, lyophilized and dissolved in DMSO to make $10 \mathrm{mM}$ stock solution of complexes. The formation of the complexes was confirmed by a shift in the retention time from the apo ligand and the purity of the complexes was confirmed by HPLC. HPLC traces for the complexes $2 \mathrm{Nd}, 5 \mathrm{Nd}, \mathbf{8 N d}$ and $\mathbf{1 1} \mathrm{Nd}$ are shown below (Figure $\mathrm{S} 1$ ).

\section{Complex 1Nd}

HRMS $\left(\mathrm{FAB}^{+}\right.$): Calc'd for ${ }^{142} \mathrm{NdC}_{37} \mathrm{H}_{43} \mathrm{~N}_{6} \mathrm{O}_{10} 873.21 \mathrm{~m} / \mathrm{z}$, measured $874.21 \mathrm{~m} / \mathrm{z}$ $\left(\boldsymbol{M H}^{+}\right)$with expected isotopic pattern for $\mathrm{Nd}$.

\section{Complex 2Nd}

HRMS $\left(\mathrm{FAB}^{+}\right.$): Calc'd for ${ }^{142} \mathrm{NdC}_{38} \mathrm{H}_{45} \mathrm{~N}_{6} \mathrm{O}_{10} 887.23 \mathrm{~m} / z$, measured $888.23 \mathrm{~m} / \mathrm{z}$ $\left(\mathrm{MH}^{+}\right)$with expected isotopic pattern for $\mathrm{Nd}$.

\section{Complex 3Nd}

HRMS (FAB ${ }^{+}$): Calc'd for ${ }^{142} \mathrm{NdC}_{41} \mathrm{H}_{51} \mathrm{~N}_{6} \mathrm{O}_{10} 929.27 \mathrm{~m} / \mathrm{z}$, measured $930.28 \mathrm{~m} / \mathrm{z}$ $\left(\mathrm{MH}^{+}\right)$with expected isotopic pattern for $\mathrm{Nd}$.

\section{Complex 4Nd}

HRMS $\left(\mathrm{FAB}^{+}\right.$): Calc'd for ${ }^{142} \mathrm{NdC}_{37} \mathrm{H}_{43} \mathrm{~N}_{6} \mathrm{O}_{10} 873.21 \mathrm{~m} / \mathrm{z}$, measured $874.22 \mathrm{~m} / \mathrm{z}$ $\left(\boldsymbol{M} \mathrm{H}^{+}\right)$with expected isotopic pattern for $\mathrm{Nd}$.

\section{Complex 5Nd}

HRMS $\left(\mathrm{FAB}^{+}\right.$): Calc'd for ${ }^{142} \mathrm{NdC}_{38} \mathrm{H}_{45} \mathrm{~N}_{6} \mathrm{O}_{10} 887.23 \mathrm{~m} / z$, measured $888.23 \mathrm{~m} / \mathrm{z}$ $\left(\mathrm{MH}^{+}\right)$with expected isotopic pattern for $\mathrm{Nd}$.

\section{Complex 6Nd}

HRMS $\left(\mathrm{FAB}^{+}\right.$): Calc'd for ${ }^{142} \mathrm{NdC}_{41} \mathrm{H}_{51} \mathrm{~N}_{6} \mathrm{O}_{10} 929.27 \mathrm{~m} / z$, measured $930.28 \mathrm{~m} / z$ $\left(\mathrm{MH}^{+}\right)$with expected isotopic pattern for $\mathrm{Nd}$.

\section{Complex 7Nd}

HRMS $\left(\mathrm{FAB}^{+}\right.$): Calc'd for ${ }^{142} \mathrm{NdC}_{37} \mathrm{H}_{45} \mathrm{~N}_{6} \mathrm{O}_{10} 875.23 \mathrm{~m} / z$, measured $876.24 \mathrm{~m} / \mathrm{z}$ $\left(\boldsymbol{M H}^{+}\right)$with expected isotopic pattern for $\mathrm{Nd}$.

\section{Complex 8Nd}

HRMS (FAB ${ }^{+}$): Calc'd for ${ }^{142} \mathrm{NdC}_{38} \mathrm{H}_{47} \mathrm{~N}_{6} \mathrm{O}_{10} 889.24 \mathrm{~m} / z$, measured $890.25 \mathrm{~m} / z$ $\left(\boldsymbol{M H}^{+}\right)$with expected isotopic pattern for $\mathrm{Nd}$.

\section{Complex 9Nd}

HRMS $\left(\mathrm{FAB}^{+}\right.$): Calc'd for ${ }^{142} \mathrm{NdC}_{41} \mathrm{H}_{53} \mathrm{~N}_{6} \mathrm{O}_{10} 931.29 \mathrm{~m} / z$, measured $932.30 \mathrm{~m} / \mathrm{z}$ $\left(\mathrm{MH}^{+}\right)$with expected isotopic pattern for $\mathrm{Nd}$.

\section{Complex 10Nd}

HRMS $\left(\mathrm{FAB}^{+}\right.$): Calc'd for ${ }^{142} \mathrm{NdC}_{37} \mathrm{H}_{45} \mathrm{~N}_{6} \mathrm{O}_{10} 875.23 \mathrm{~m} / z$, measured $876.24 \mathrm{~m} / \mathrm{z}$ $\left(\boldsymbol{M} \mathrm{H}^{+}\right)$with expected isotopic pattern for $\mathrm{Nd}$.

\section{Complex 11Nd}

HRMS (FAB ${ }^{+}$): Calc'd for ${ }^{144} \mathrm{NdC}_{38} \mathrm{H}_{47} \mathrm{~N}_{6} \mathrm{O}_{10} 891.25 \mathrm{~m} / \mathrm{z}$, measured $892.26 \mathrm{~m} / \mathrm{z}$ $\left(\mathrm{MH}^{+}\right)$with expected isotopic pattern for $\mathrm{Nd}$.

\section{Complex 12Nd}

HRMS $\left(\mathrm{FAB}^{+}\right.$): Calc'd for ${ }^{142} \mathrm{NdC}_{41} \mathrm{H}_{53} \mathrm{~N}_{6} \mathrm{O}_{10} 931.29 \mathrm{~m} / z$, measured $932.30 \mathrm{~m} / \mathrm{z}$ $\left(\mathrm{MH}^{+}\right)$with expected isotopic pattern for $\mathrm{Nd}$. 


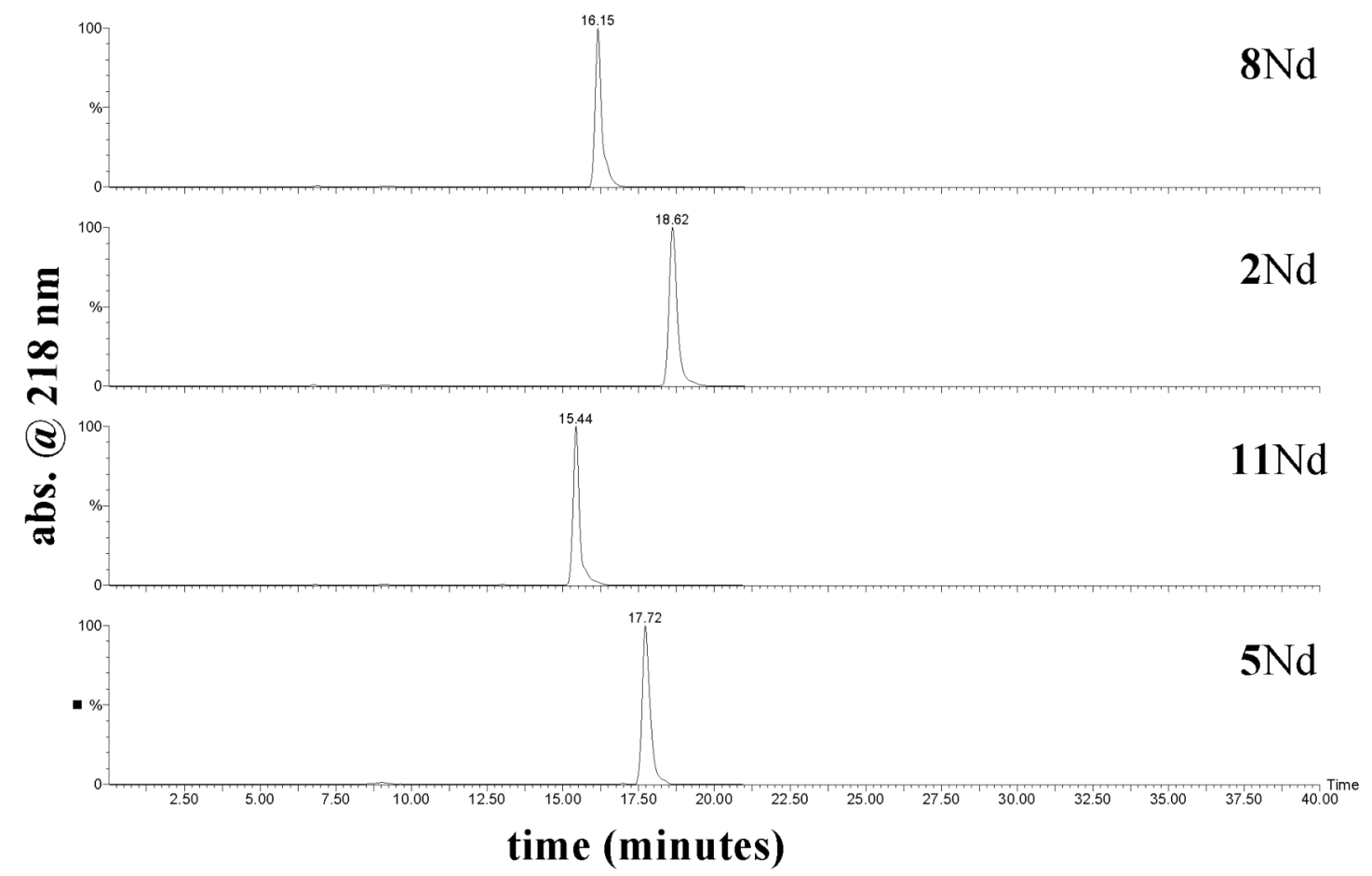

Figure S1. HPLC traces of the complexation.

\section{Part II: Photophysical Measurements}

\section{UV/VIS Absorption Measurement}

Ultraviolet spectra were measured on a Molecular Devices SPECTRAmax Plus 384 UV-Visible spectrophotometer operated through a Dell Pentium PC by SOFTmax software. All measurements were taken in $100 \mathrm{mM}$ phosphate buffer $\mathrm{pH} 7$.

\begin{tabular}{|c|c|c|c|c|c|}
\hline $\begin{array}{c}\text { Ketone } \\
\text { complexes }\end{array}$ & $\lambda_{\text {abs }}(\mathrm{nm})$ & $\varepsilon\left(\mathrm{M}^{-1} \mathrm{~cm}^{-1}\right)$ & $\begin{array}{c}\text { Alcohol } \\
\text { complexes }\end{array}$ & $\lambda_{\text {abs }}(\mathrm{nm})$ & $\varepsilon\left(\mathrm{M}^{-1} \mathrm{~cm}^{-1}\right)$ \\
\hline $\mathbf{1 N d}$ & 419 & 15400 & $\mathbf{7 N d}$ & 395 & 22200 \\
\hline $\mathbf{2 N d}$ & 419 & 15250 & $\mathbf{8 N d}$ & 395 & 21200 \\
\hline $\mathbf{3 N d}$ & 424 & 9300 & $\mathbf{9 N d}$ & 398 & 18700 \\
\hline $\mathbf{4 N d}$ & 417 & 15900 & $\mathbf{1 0 N d}$ & 398 & 19500 \\
\hline $\mathbf{5 N d}$ & 416 & 13700 & $\mathbf{1 1 N d}$ & 398 & 17400 \\
\hline $\mathbf{6 N d}$ & 415 & 9200 & $\mathbf{1 2 N d}$ & 400 & 15600 \\
\hline $\mathbf{2}$ & 420 & 15500 & $\mathbf{8}$ & 400 & 20600 \\
\hline $\mathbf{5}$ & 420 & 11300 & $\mathbf{1 1}$ & 397 & 18300 \\
\hline
\end{tabular}

\section{Near-IR Luminescent Measurement}

Near-IR emission spectra were recorded on a modified SPEX Fluorolog 2 (J. Y. Horiba, Edison, NJ) equipped with a cooled NIR sensitive PMT (H9170-45; Hamamatzu). As an excitation source, a $450 \mathrm{~W}$ Xe-lamp (Osram) in conjunction with a 
double-grating monochromator was used. The measurements were performed in a $5 \times 5$ $\mathrm{mm}$ quartz cell at a concentration of $5 \mu \mathrm{M}$ of the complex in $100 \mathrm{mM}$ phosphate buffer at $\mathrm{pH}$ 7. Excitation wavelength $=395 \mathrm{~nm}$.

\begin{tabular}{|c|c|c|c|c|c|}
\hline $\begin{array}{c}\text { Ketone } \\
\text { complexes }\end{array}$ & $\lambda_{\text {em }}(\mathrm{nm})$ & R. I. & $\begin{array}{c}\text { Alcohol } \\
\text { complexes }\end{array}$ & $\boldsymbol{\lambda}_{\text {em }}(\mathrm{nm})$ & R. I. \\
\hline $\mathbf{1 N d}$ & 1058 & 0.025 & $\mathbf{7 N d}$ & 1058 & 0.90 \\
\hline $\mathbf{2 N d}$ & 1058 & 0.022 & $\mathbf{8 N d}$ & 1058 & 1 \\
\hline $\mathbf{3 N d}$ & 1058 & 0.006 & $\mathbf{9 N d}$ & 1058 & 0.33 \\
\hline $\mathbf{4 N d}$ & 1058 & 0.031 & $\mathbf{1 0 N d}$ & 1058 & 0.86 \\
\hline $\mathbf{5 N d}$ & 1058 & 0.019 & $\mathbf{1 1 N d}$ & 1058 & 0.82 \\
\hline $\mathbf{6 N d}$ & 1058 & 0.029 & $\mathbf{1 2 N d}$ & 1058 & 0.43 \\
\hline
\end{tabular}

The relative intensity (R.I.) values were determined by integrating the luminescence from $1020-1110 \mathrm{~nm}$ and normalizing to the complex $\mathbf{8 N d}$, the most luminescent complex (for spectra see Figures S5 - S10 and S13)

\section{Luminescence Lifetime Measurement}

Near-IR luminescence lifetimes were measured by excitation with pulses $(410 \mathrm{~nm}$, $\sim 5 \mathrm{~mJ} /$ pulse) from a Lambda Physik dye laser (FL3002; Laser dye: Stilbene 3), which was pumped with a Lambda Physik excimer laser (Lextra 50). The luminescence was collected and isolated using a filter (RG695) and a monochromator 1681B (Jobin-Yvon Inc.) and focused onto a Hamamatzu photomultiplier tube (H9170-45). The photocurrent from the PMT was stored on a digital oscilloscope (TDS 360, Tektronix).

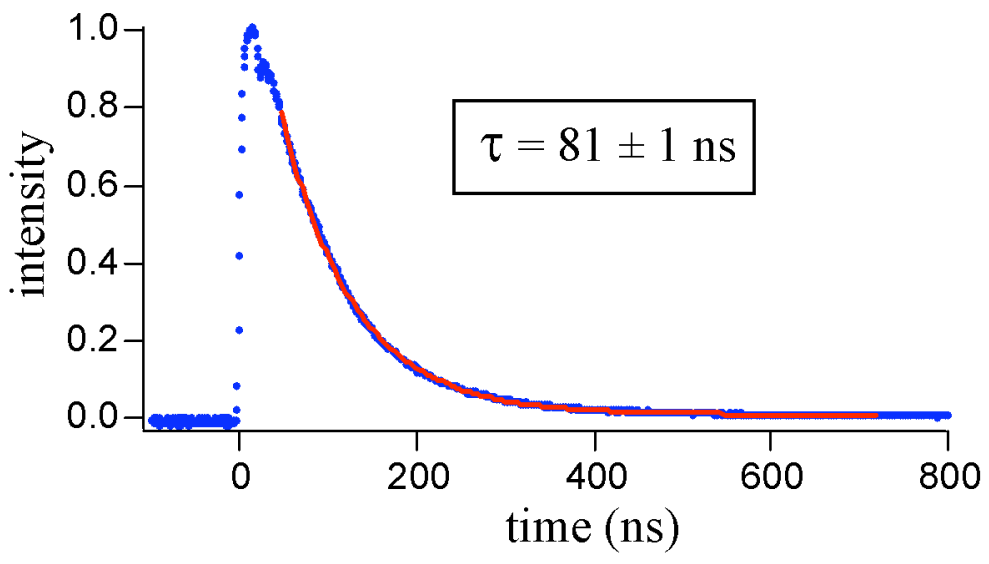

Figure S2. Representative graph of luminescence decay trace (blue) monitored at 1060 $\mathrm{nm}$ after excitation of the alcohol complex (in this case $11 \mathrm{Nd}$ ) with laser pulses at $410 \mathrm{~nm}$. Monoexponential fit (red).

\section{Luminescence Quantum Yield Measurement}

The quantum yield of the complex $8 \mathrm{Nd}$ and $11 \mathrm{Nd}$ was calculated using the formula $\phi_{\mathrm{Ln}}=\tau / \tau_{\mathrm{rad}}$ 
where $\tau=$ radiative lifetime of the complexes and $\tau_{\text {rad }}=$ pure radiative lifetime of $\mathrm{Nd}(\mathrm{III})$ $(0.25 \mathrm{~ms}){ }^{9}$

The quantum yield for the other complexes was then measured relative to $11 \mathrm{Nd}$ using a solution of the complex in $100 \mathrm{mM}$ phosphate buffer at $\mathrm{pH} 7$ with abosorbance value of 0.3 at $395 \mathrm{~nm}$ with a $1 \mathrm{~cm}$ path length and taking the integrated emission values between $1020 \mathrm{~nm}-1100 \mathrm{~nm}$ (Figure S14).

\begin{tabular}{|c|c|c|c|}
\hline $\begin{array}{c}\text { Alcohol } \\
\text { complexes }\end{array}$ & $\lambda_{\text {em }}(\mathrm{nm})$ & $\begin{array}{c}\text { Integrated emission } \\
\text { (normalized to 11Nd) }\end{array}$ & $\begin{array}{c}\text { Quantum } \\
\text { Yield (\%) }\end{array}$ \\
\hline $\mathbf{7 N d}$ & 1058 & 1.04 & 0.034 \\
\hline $\mathbf{8 N d}$ & 1058 & 0.98 & 0.032 \\
\hline $\mathbf{9 N d}$ & 1058 & 0.68 & 0.022 \\
\hline $\mathbf{1 0 N d}$ & 1058 & 1.05 & 0.034 \\
\hline $\mathbf{1 1 N d}$ & 1058 & 1 & 0.033 \\
\hline $\mathbf{1 2 N d}$ & 1058 & 0.69 & 0.023 \\
\hline
\end{tabular}

\section{Fluorescence Emission Measurement}

Fluorescence measurements were taken on a Jobin Yvon Fluorolog 3 fluorescence spectrofluorometer, using a $390 \mathrm{~nm}$ long-pass filter to remove scattered second order excitation light. To measure the relative fluorescence quantum yield of the chromophore with and without the $\mathrm{Nd}(\mathrm{III})$ ion, the measurement was done on solutions of $\mathbf{8 , 8} \mathbf{8 N d}, \mathbf{1 1}$ and $11 \mathrm{Nd}$ with absorbance of 0.2 at $395 \mathrm{~nm}$ in $100 \mathrm{mM}$ phosphate buffer at $\mathrm{pH}$ 7. The samples were excited at $395 \mathrm{~nm}$ and the emission from 420 to $700 \mathrm{~nm}$ was recorded. The integrated intensity for $430-650 \mathrm{~nm}$ was calculated and normalized to the corresponding apo compound (for spectra, see figures S11 and S12).

\begin{tabular}{|c|c|c|c|}
\hline Compound & $\begin{array}{c}\text { Relative } \\
\text { fluorescencequantum } \\
\text { yield }\end{array}$ & Compound & $\begin{array}{c}\text { Relative } \\
\text { fluorescence } \\
\text { quantum yield }\end{array}$ \\
\hline $\mathbf{8}$ & 1 & $\mathbf{8 N d}$ & 0.15 \\
\hline $\mathbf{1 1}$ & 1 & $\mathbf{1 1 N d}$ & 0.1 \\
\hline
\end{tabular}

\section{Phosphorescence Emission Measurement}

Phosphorescence measurements were performed on a Jobin Yvon Fluorolog 3 fluorescence spectrofluorometer using a pulsed Xe-lamp for excitation. Solutions of the ketone/alcohol pair, $\mathbf{5}$ and 11, were prepared in doubly-deionized water with absorbance values of 0.2 (3 mm path length) at the excitation wavelength, $395 \mathrm{~nm}$. To measure the phosphorescence, the sample solutions were placed into Suprasil quartz tubes $(3 \mathrm{~mm}$ diameter) and cooled to $77 \mathrm{~K}$ with liquid nitrogen. The phosphorescence maxima at $77 \mathrm{~K}$ were found to be at $542 \mathrm{~nm}$ for the ketone (5) and $540 \mathrm{~nm}$ for the alcohol derivative (11). 


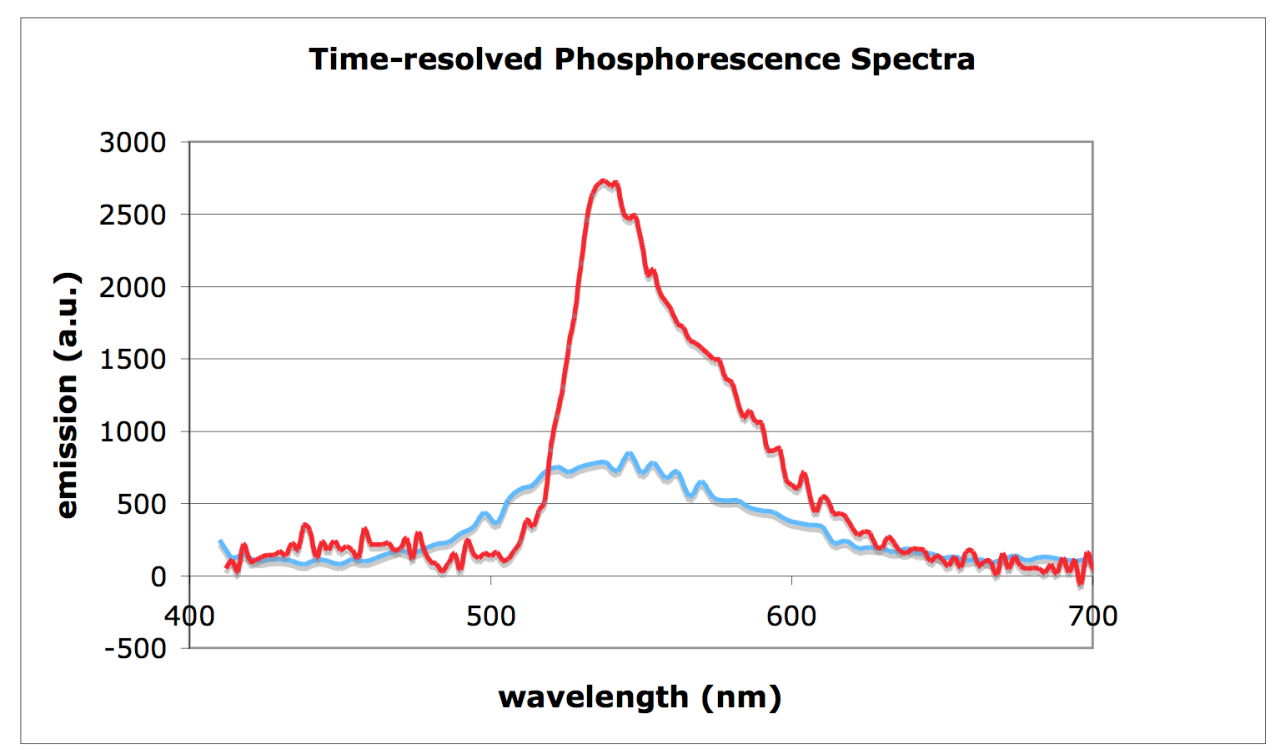

Figure S3. Time-gated phosphorescence spectra of ligands 5 (red) and 11 (blue) in doubly-deionized water at $77 \mathrm{~K}$ recorded with delay times of $0.4 \mathrm{~ms}(\mathbf{5})$ and $50 \mathrm{~ms}$ (11) after the excitation pulse at $395 \mathrm{~nm}$ using gates of $0.2 \mathrm{~ms}(\mathbf{5})$ and $50 \mathrm{~ms}$ (11).

\section{Part III: Enzymology}

\section{Determination of Steady State Kinetic Parameters for the AKR1C's}

The Michaelis and catalytic constants $\left(K_{m}\right.$ and $\left.k_{c a t}\right)$ of the complexes were determined as follows. To a STARNA semi-micro fluorometer cell (with 4 polished windows) was added $70 \mu \mathrm{L}$ of $1 \mathrm{M}$ potassium phosphate buffer (pH 7), $612 \mu \mathrm{L}$ doubly deionized water and $14 \mu \mathrm{L}$ of $12.5 \mathrm{mM}$ NADPH solution. After mixing the components thoroughly, $3.5 \mu \mathrm{L}$ of freshly prepared stock solutions of the complexes (in DMSO) of different concentrations were added to achieve assay concentrations ranging from $0.2 K_{m}$ to about $3 K_{m}-5 K_{m}$. To initiate the reduction, 2 to $4 \mu \mathrm{L}$ of $0.34 \mathrm{mg} / \mathrm{mL}$ AKR1C2 was then added to the cuvette. Fluorescence $(510 \mathrm{~nm})$ arising from the respective alcohol reduction product was monitored over the course of $240 \mathrm{~s}$ with excitation at $395 \mathrm{~nm}$. The rate of product formation, expressed in units of nanomoles/minute was calculated according to previously published procedures: ${ }^{8}$

Initial rate $=\left[n_{s t} \times\left\{\left(F_{t}-F_{0}\right) / F_{s t}\right\}\right] / t$

Where $F_{t}$ and $F_{0}$ represent fluorescence at times $t$ and 0 minutes, $n_{s t}$ is the nanomoles in a solution of a known concentration of product and $F_{s t}$ is the fluorescence resulting from $n_{s t}$ of product. Kinetic parameters were approximated by KaleidaGraph (Synergy Software, Reading, USA) nonlinear regression analysis performed to fit the untransformed data to a hyperbolic function as originally described. ${ }^{8}$ Reported enzymatic parameters are the average of three independent determinations performed in duplicates.

The enzymatic reduction of the complexes was correlated to an increase in the $\mathrm{Nd}(\mathrm{III})$ emission at $1060 \mathrm{~nm}$ by qualitative enzyme assays performed on the instrument that is specially outfitted with near-IR filters. For practical reasons, detailed kinetic studies, i.e. the constants $\left(K_{m}\right.$ and $\left.k_{c a t}\right)$ were determined via fluorescence increase of the chromophore on a standard visible fluorescence instrument. The fluorescence growth has 
been determined to have a linear correlation with the concentration of the alcohol product. The enzymatic conversion of the ketone complexes to the corresponding alcohol was confirmed by reverse-phase HPLC.

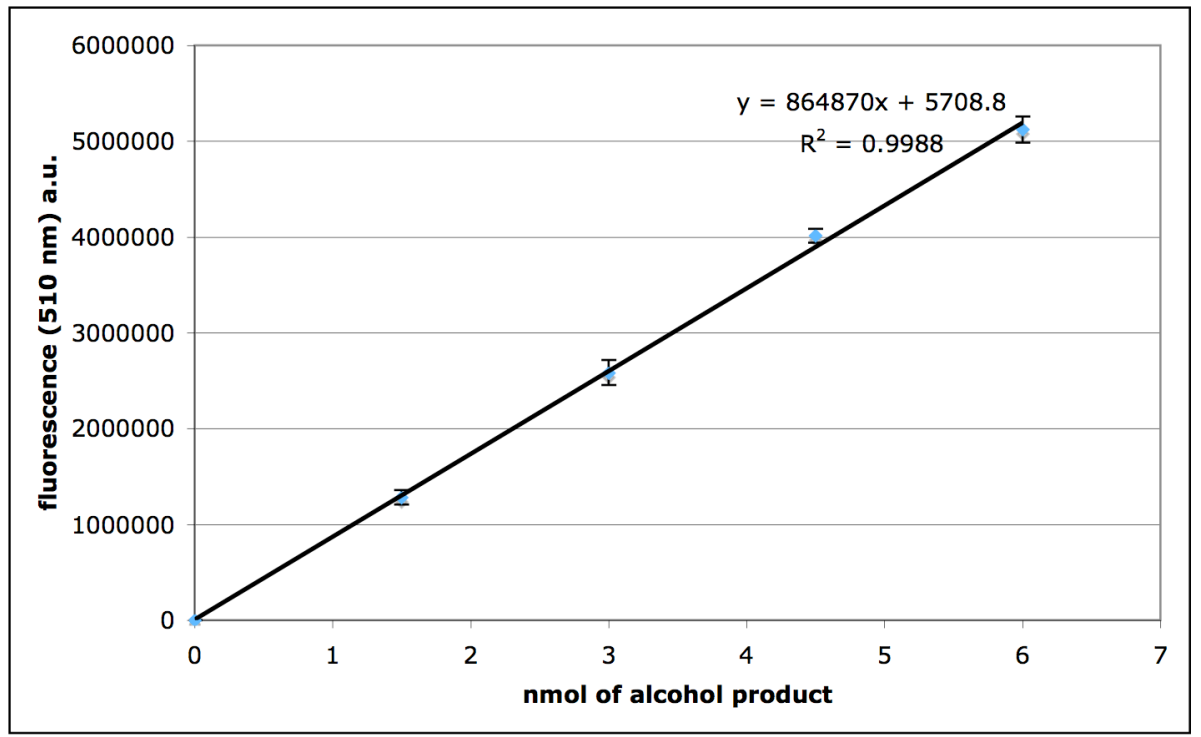

Figure S4. A representative calibration curve showing linear correlation of fluorescence at $510 \mathrm{~nm}$ with nmol of alcohol product formed. The error bar is derived from three measurements. 


\section{Part IV: Luminescence and Fluorescence Spectra}

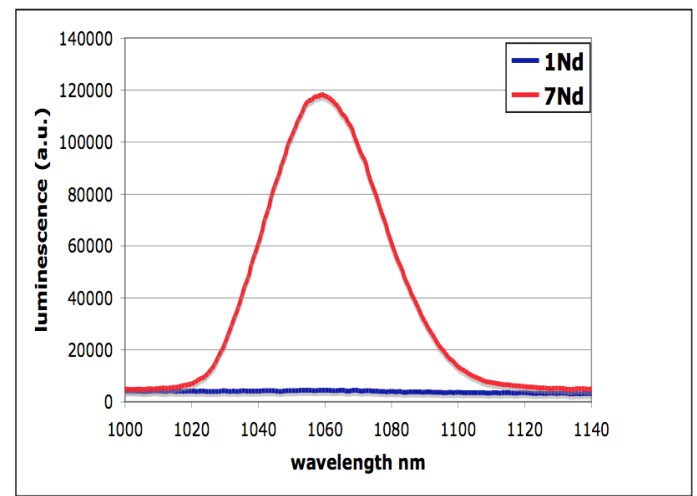

Figure S5. Luminescence spectra of $1 \mathrm{Nd}$ and $7 \mathrm{Nd}$.

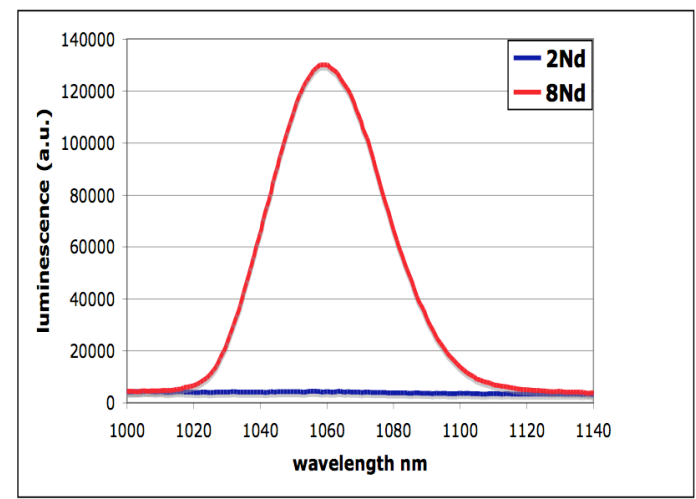

Figure S6. Luminescence spectra of $2 \mathrm{Nd}$ and $8 \mathrm{Nd}$.

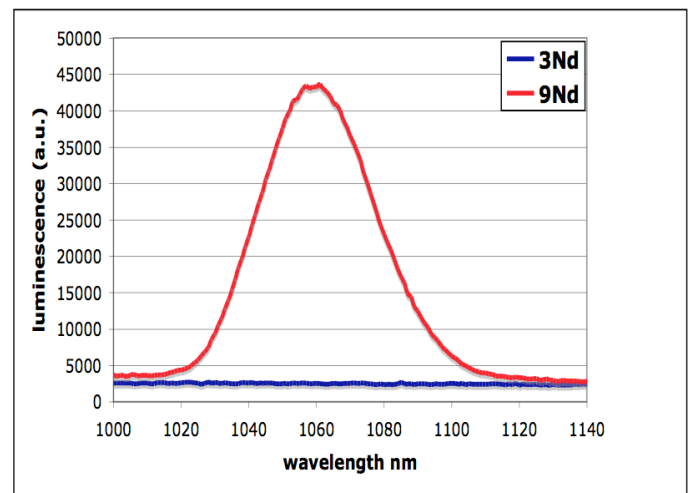

Figure S7. Luminescence spectra of $3 \mathrm{Nd}$ and $9 \mathrm{Nd}$.

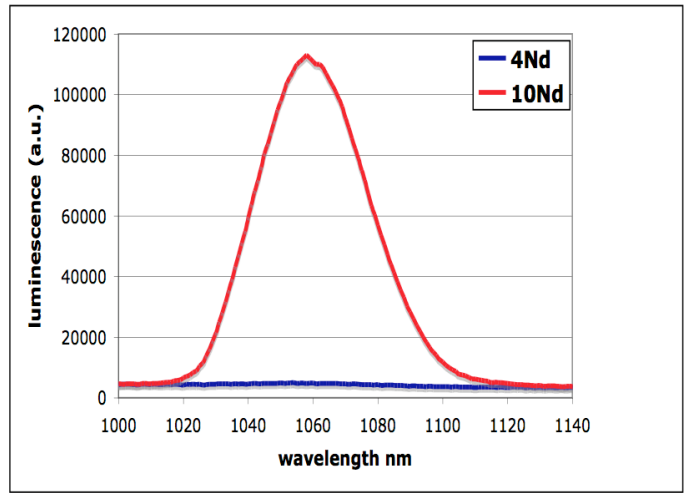

Figure S8. Luminescence spectra of $4 \mathrm{Nd}$ and $10 \mathrm{Nd}$.

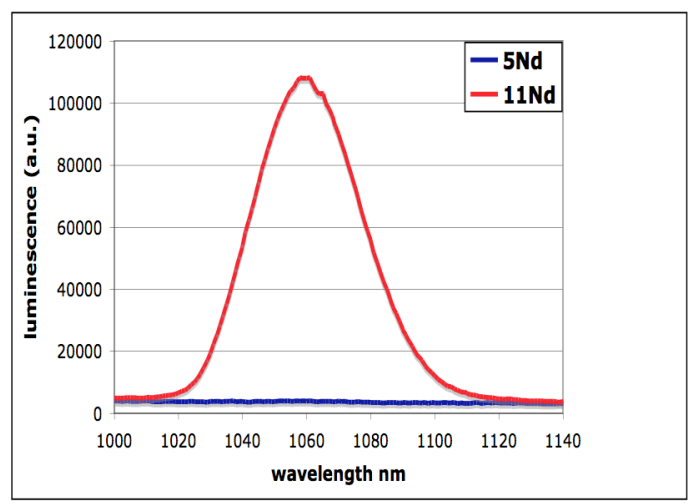

Figure S9. Luminescence spectra of $5 \mathrm{Nd}$ and $11 \mathrm{Nd}$.

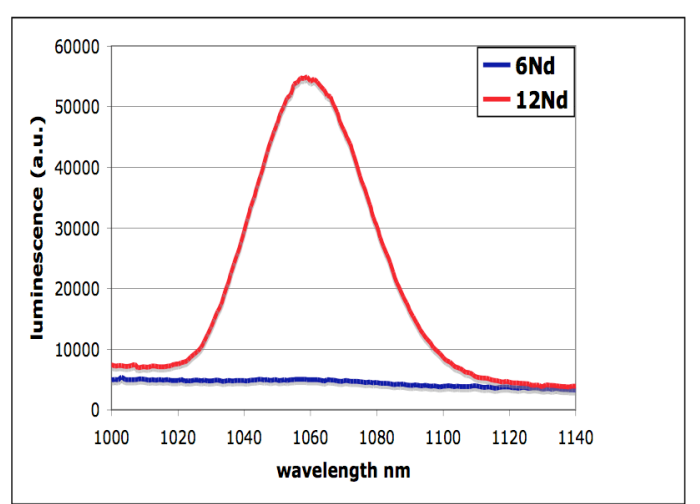

Figure S10. Luminescence spectra of $6 \mathrm{Nd}$ and $12 \mathrm{Nd}$. 


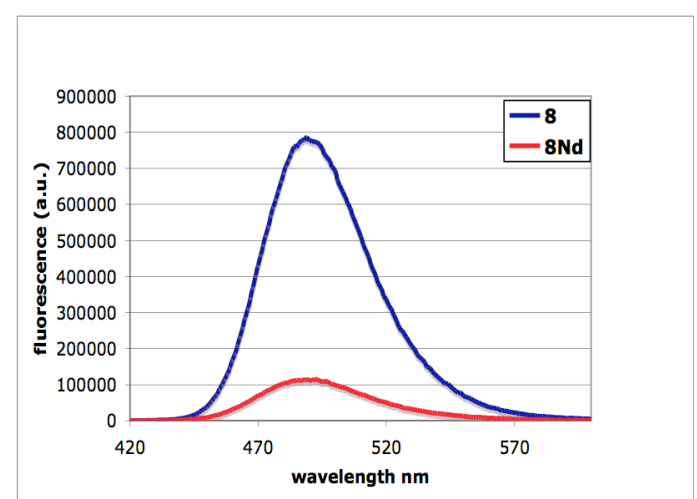

Figure S11. Fluorescence spectra of 8 (apo ligand) and $\mathbf{8} \mathrm{Nd}$.

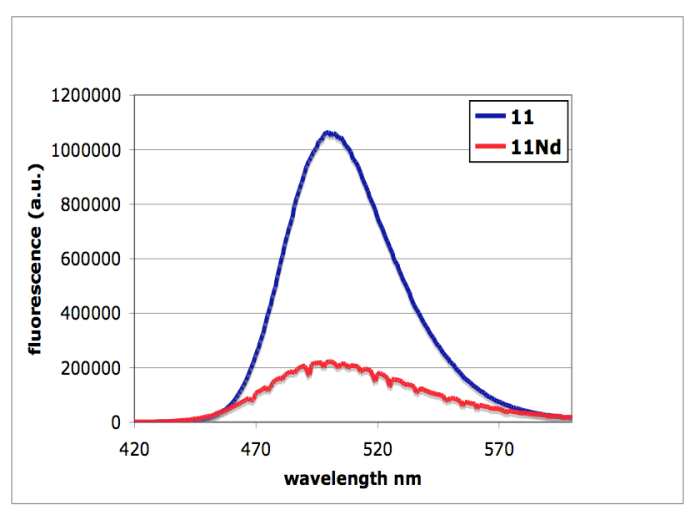

Figure S12. Fluorescence spectra of 11 (apo ligand) and $11 \mathrm{Nd}$.

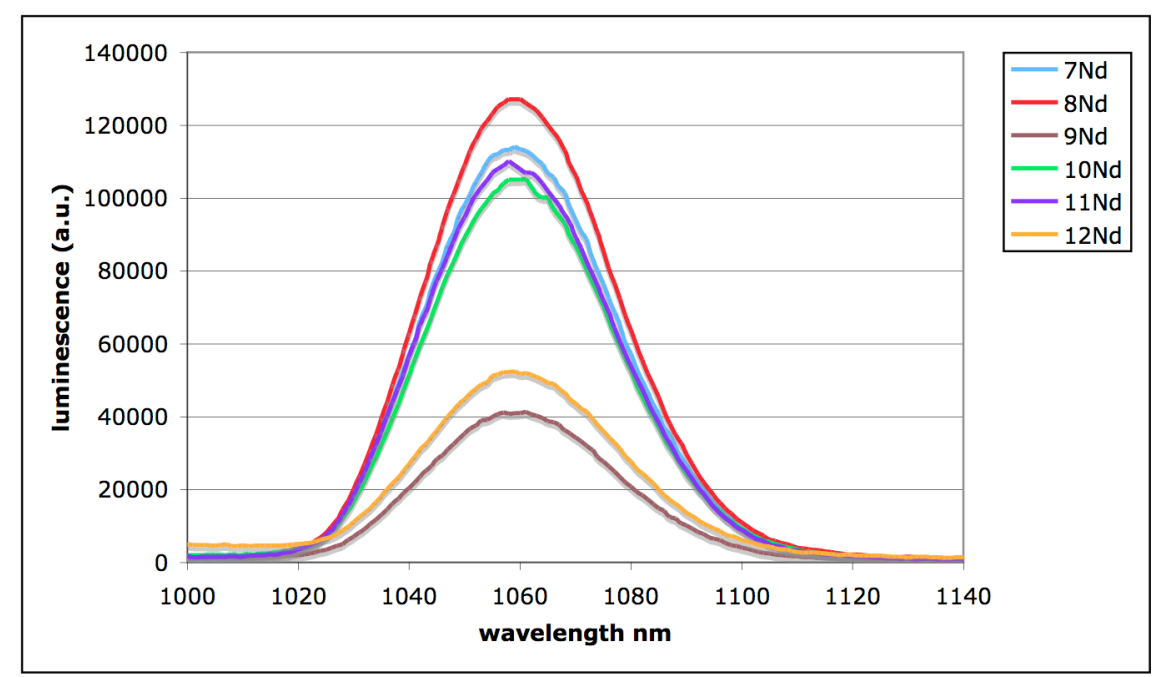

Figure S13. Luminescence spectra of complexes $7 \mathrm{Nd}-\mathbf{1 2} \mathrm{Nd}$.

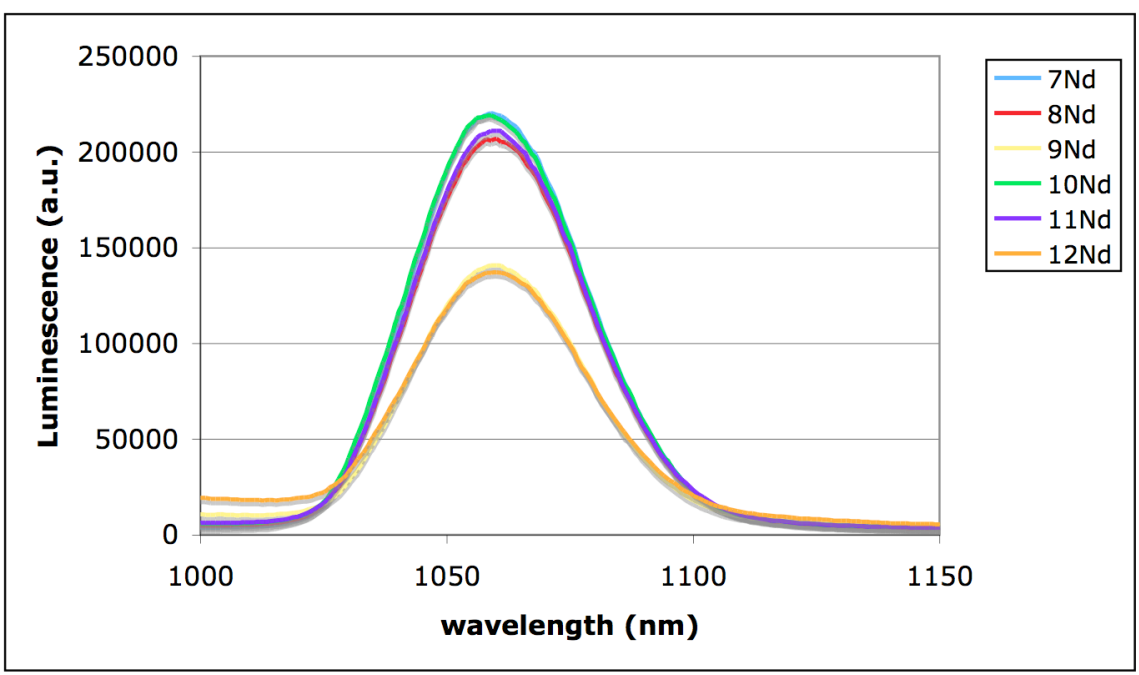

Figure S14. Luminescence spectra of complexes $7 \mathrm{Nd}-12 \mathrm{Nd}$ taken in solutions of 0.3 absorbance at $395 \mathrm{~nm}$ in $100 \mathrm{mM}$ phosphate buffer $\mathrm{pH} 7$. 
1. Arcadi, A.; Bernocchi, E.; Burini, A.; Cacchi, S.; Marinelli, F.; Pietroni, B. Tetrahedron 1988, 44, $481-490$.

2. Naka, T.; Koide, K. Tetrahedron Letters 2003, 44, 443 - 445.

3. Torisawa, Y.; Nishi, T.; Minamikawa, J. Bioorg. Med. Chem. Lett. 2002, 12, 387 $-390$.

4. Atkins, R. L.; Bliss, D. E., J. Org. Chem. 1978, 43, 1975 - 1980.

5. Dueholm, K.L.; Egholm, M.; Buchardt, O. Org. Prep. Proc. Intl. 1993, 25, 457 461.

6. Busnel, O.; Bi, L.; Dali, H.; Cheguillaume, A.; Chevance, S.; Bondon, A.; Muller, S.; Baudy-Floc'h, M. J. Org. Chem. 2006, 70, 10701 - 10708.

7. Aarons, R. J., Notta, J. K.; Meloni, M. M.; Feng, J.; Vidyasagra, R.; Narvainen, J.; Allan, S.; Spencer, N.; Kauppinen, R. A.; Snaith, J. S.; Faulkner, S. Chem. Commun. 2006, $909-911$.

8. Wierzchowski, J.; Dafeldecker, W.P.; Holmquist, B.; Vallee, B.L. Anal. Biochem 1989, $178,57-62$.

9. Hebbink, G. A.; Grave, L.; Woldering, L. A.; Reinhoudt, D. N.; van Veggel, F. C. J. M. J. Phys, Chem. A. 2003, 107, $2483-2491$. 


\section{Part V: NMR Spectra of Selected Compounds}

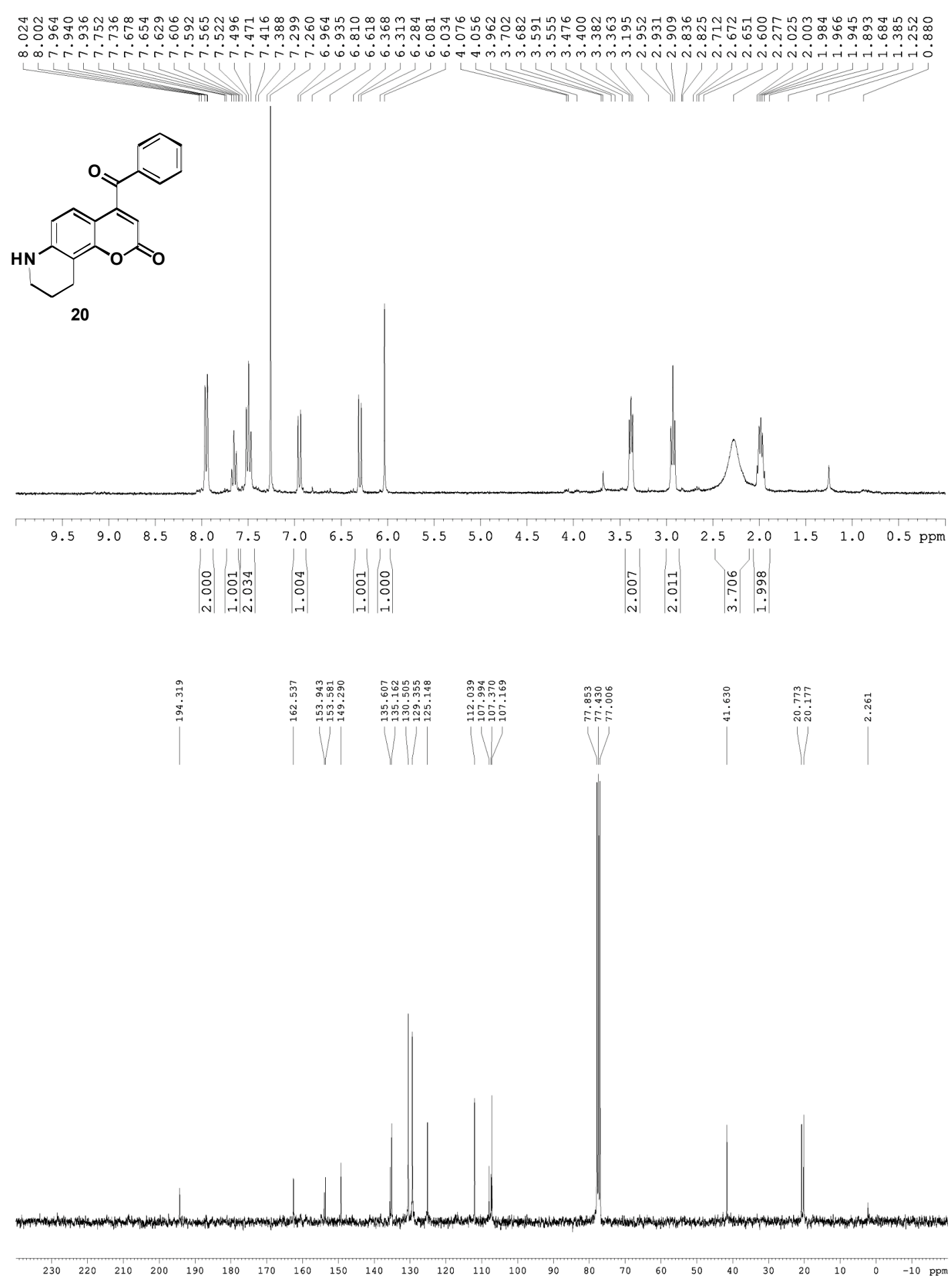




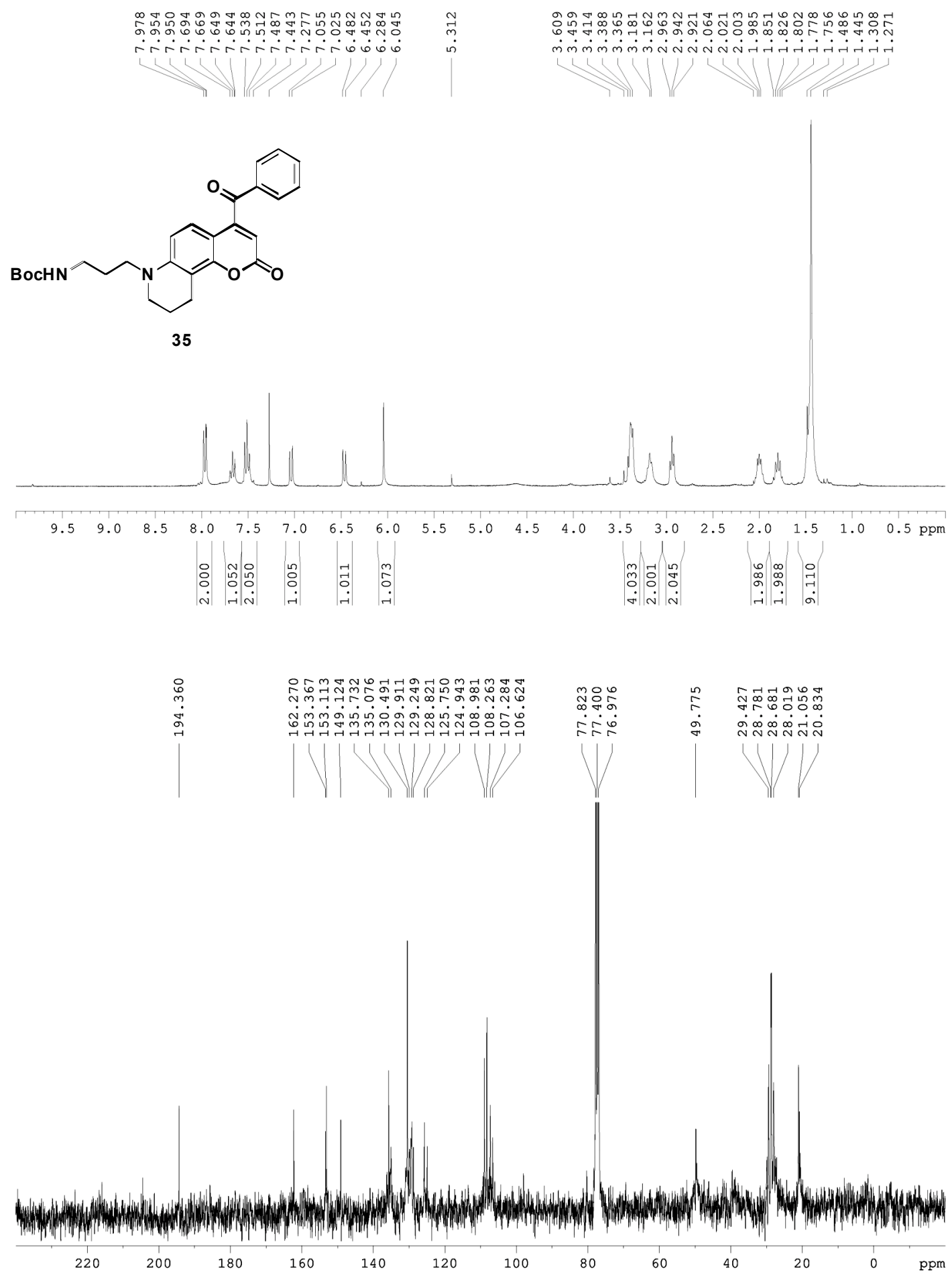




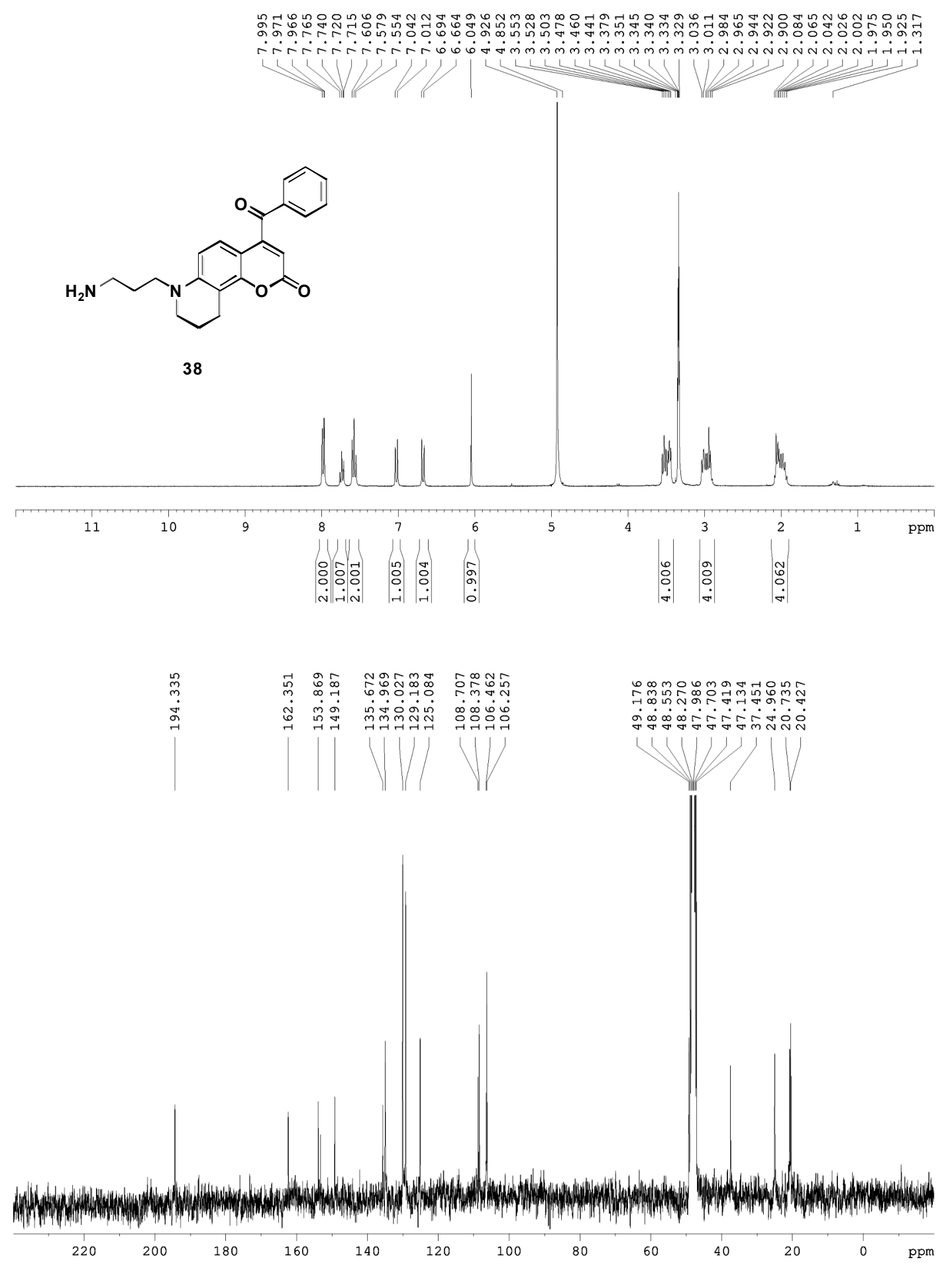




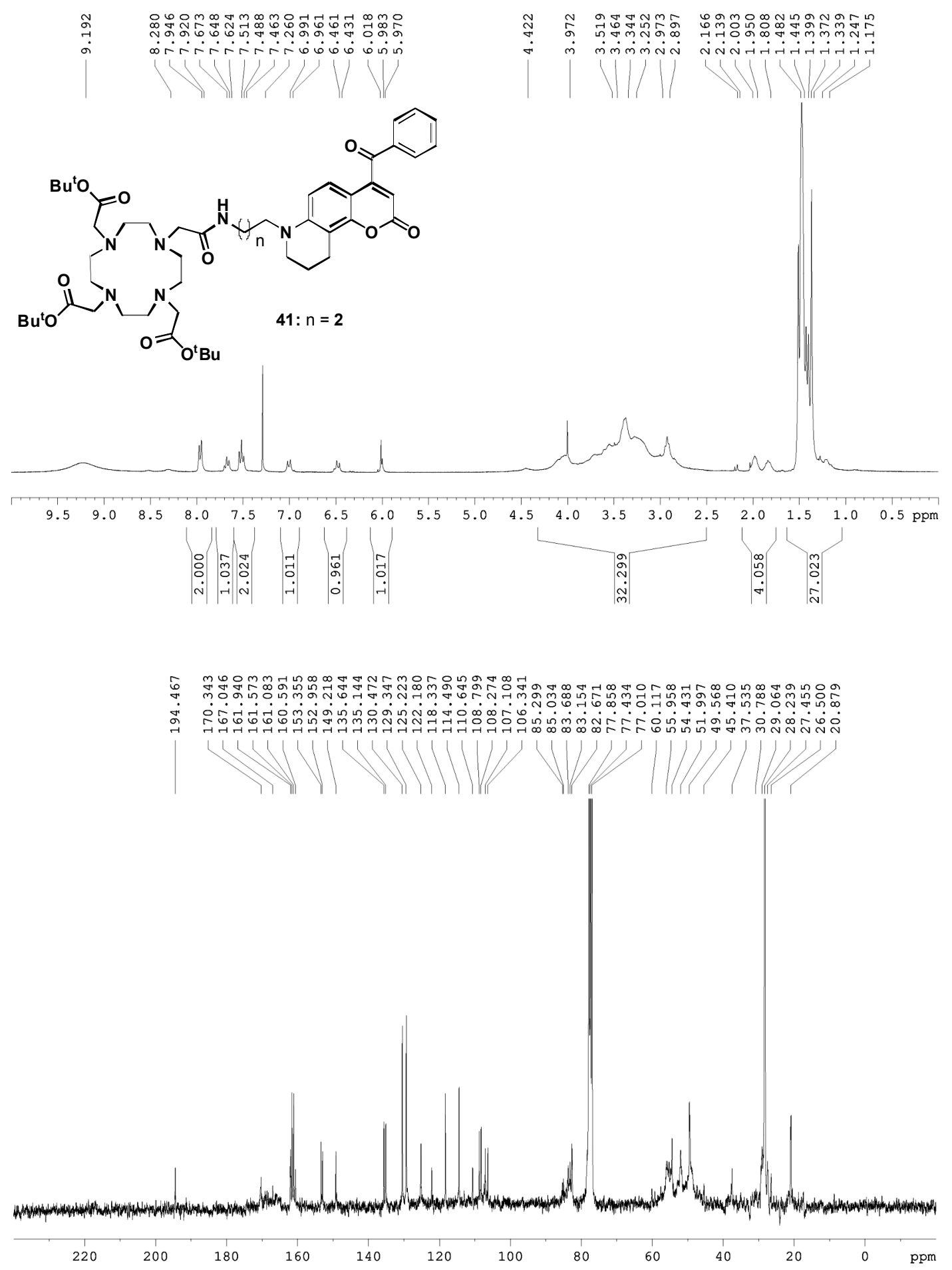



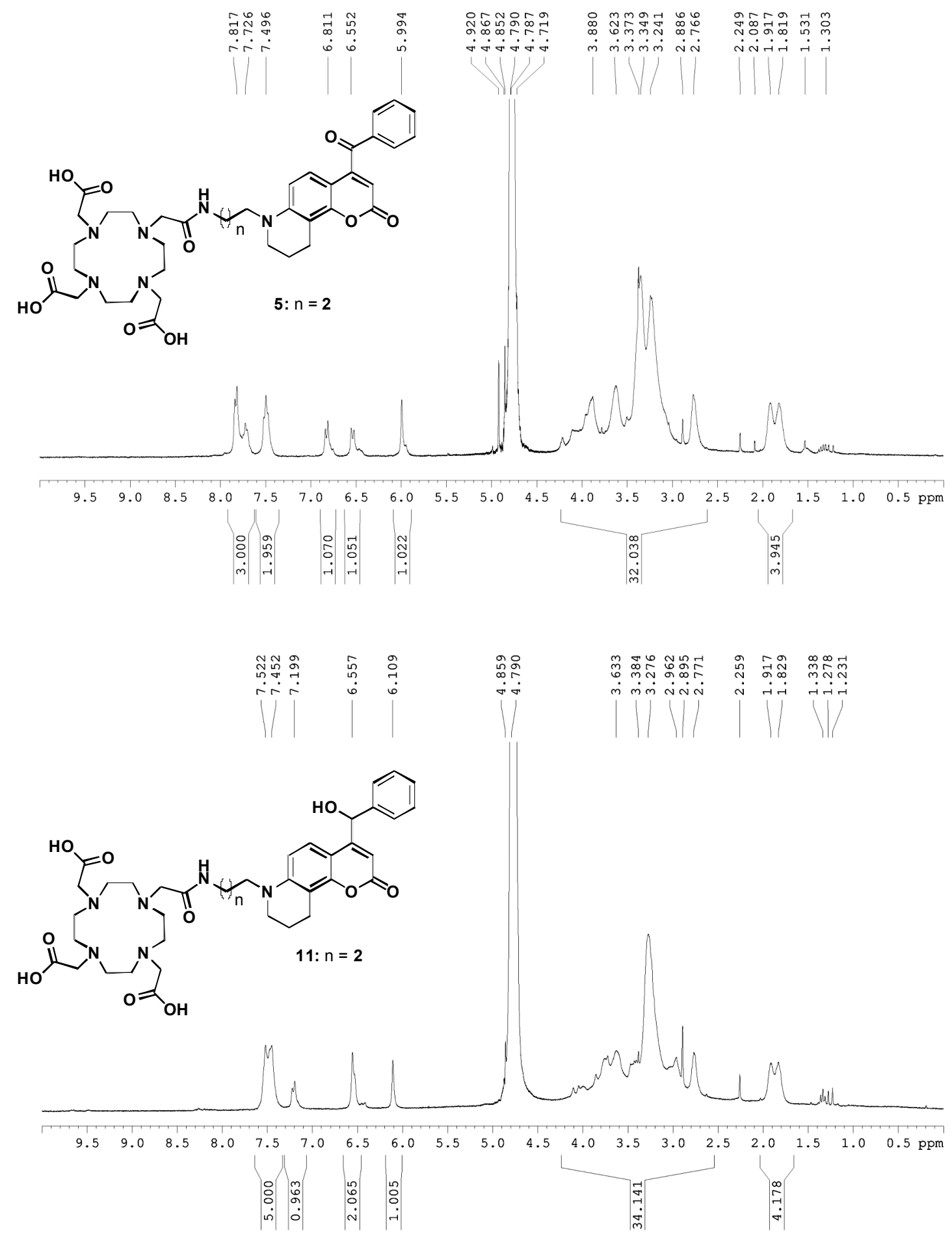

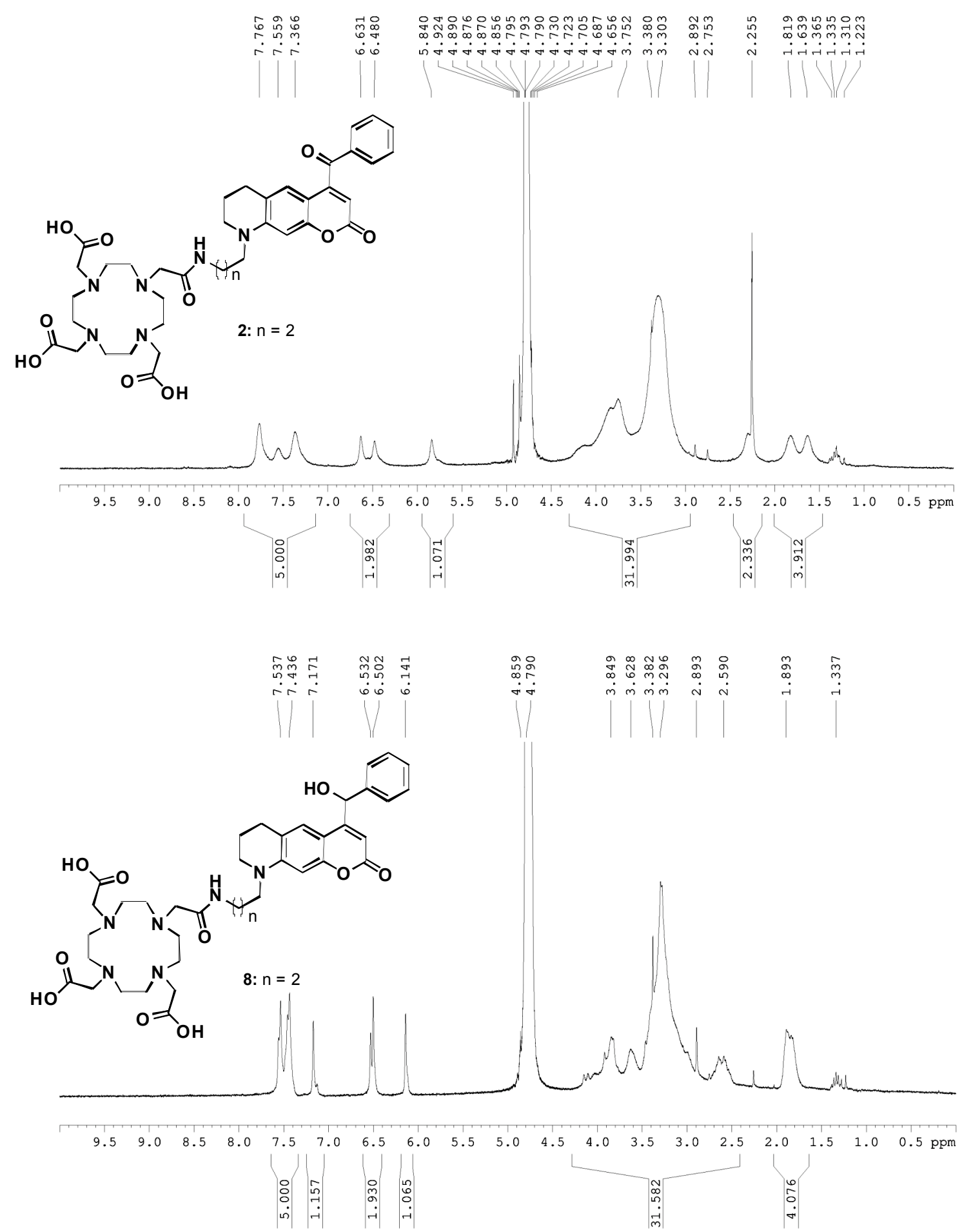